\title{
THE HOUSING STOCK, HOUSING PRICES, AND USER COSTS: THE ROLES OF LOCATION, STRUCTURE, AND UNOBSERVED QUALITY*
}

\author{
By Jonathan Halket, Lars Nesheim, and Florian Oswald ${ }^{1}$ \\ Texas A\&M, U.S.A.; University of Essex and CeMMAP, United Kingdom; University College \\ London and CeMMAP, United Kingdom; Sciences Po, France
}

\begin{abstract}
Which housing characteristics are important for understanding homeownership rates? How are housing characteristics priced in rental and owner-occupied markets? What can answers to these questions tell us about economic theories of homeownership? Using the English Housing Survey, we estimate a selection model of property allocations to the owner-occupied and rental sectors. Structural characteristics and unobserved quality are important for selection. Location is not. Accounting for selection is important for rent-toprice ratio estimates and explains some puzzling correlations between rent-to-price ratios and homeownership rates. These patterns are consistent with, among others, hypotheses of rental market contracting frictions related to housing maintenance.
\end{abstract}

\section{INTRODUCTION}

In this article, we ask a set of very simple questions: Which housing characteristics are important for the allocation of properties to the rental and owner-occupied markets? Conditional on that allocation, how are housing characteristics priced in the rental and owneroccupied markets? And what can the answers to the previous questions tell us about economic theories of homeownership?

The housing stock is one of the most important real assets in any economy, and therefore, the allocation and pricing of that stock is an important determinant of both economic performance and consumer welfare. Yet, surprisingly little is known empirically about the factors that determine whether a housing unit is owner-occupied or is owned by a landlord. Nor do we know which housing characteristics are valued more highly by owner-occupiers and which are valued more highly by landlords nor much about how houses' relative asset values and yields vary with their characteristics.

Our approach to answer these questions is straightforward. We model an economy as endowed with a set of properties. Landlords and owner-occupiers take prices and rents as given. A property ends up in either the rental or owner-occupied sector depending on which hous-

\footnotetext{
*Manuscript received September 2017; revised June 2020.

${ }^{1}$ We thank the editor, four anonymous referees, and Randal Verbrugge for helpful comments on an earlier draft. This research was supported by the UK Economic and Social Research Council through the Centre for Microdata Methods and Practice (CeMMAP grant number ES/I034021/1), through an ESRC transformative research grant, grant number ES/M000486/1, and ESRC Large Research Grant ES/P008909/1. The work is based on data from the English Housing Survey 2008-2014 (Department for Communities and Local Government, 2017). The data are Crown Copyright and are reproduced with the permission of the controller of HMSO and Queen's Printer for Scotland. The use of the data in this work does not imply the endorsement of ONS, DCLG, the UK Data Service, nor the UK Data Archive in relation to the interpretation or analysis of the data. Although all efforts are made to ensure the quality of the materials, neither the original data creators, depositors or copyright holders, the funders of the data collections, nor the UK Data Archive, nor the UK Data Service bear any responsibility for the accuracy or comprehensiveness of these materials. Please address correspondence to: Jonathan Halket, Texas A, and M, U.S.A.; University of Essex and CeMMAP, U.K. E-mail: jonathan@halket.com.
}

(C) (2020) by the Economics Department of the University of Pennsylvania and the Osaka University Institute of Social and Economic Research Association

This is an open access article under the terms of the Creative Commons Attribution License, which permits use, distribution and reproduction in any medium, provided the original work is properly cited. 
ing sector values the property more. We then use a rich micro data set to estimate a selection model of the allocation of properties (not households) to sectors along with sector-specific hedonic models of prices and rents, exploiting the tremendous variation in dwelling characteristics, prices, rents, and ownership rates within the greater London metropolitan area between 2008 and 2012.

We find that landlords and owner-occupiers value observable locational characteristics similarly but observable physical characteristics, like the size of the property, differently, even though rent-to-price ratios vary systematically along all dimensions. Also some unobservable characteristics are valued differently and others are valued similarly. We then analyze the joint implications of these results in the context of the simplest possible dynamic setting.

More specifically, we find that:

(1) Observable physical characteristics of a property like dwelling type and size are by far the most important determinants of the probability of being in the owner-occupied sector. Housing units with high-value physical attributes (large or more detached dwellings) are more likely to be owner-occupied. At the same time, these "large" properties have higher rent-to-price ratios than smaller properties. From a consumer's perspective, this is intuitive. Owner-occupancy is more likely to be "purchased" when its relative price is lower. However, from a supply-side perspective, these empirical facts have more interesting implications. Despite relatively high gross rental yields, landlords are less likely to buy and let out properties with high-value physical characteristics. Revealed preference together with these facts, which are fairly stable over time despite large changes in property prices, implies that rental sector user costs of housing capital increase with property size faster than owner-occupied user costs.

(2) Location is relatively unimportant for the likelihood of being owner-occupied after controlling for physical characteristics. However, rent-to-price ratios vary significantly with location. Some features of the rent-to-price patterns are unstable over time that may reflect time- and location-dependent expectations of capital gains.

(3) Modeling and measuring differences in unobserved quality is essential for understanding which properties become rentals and at what price. Selection into sectors depends on both observed and unobserved characteristics. In particular, we find that the data reject unidimensional models of unobserved quality and that the different elements of unobserved quality are differentially correlated with selection. On average, rentals have lower unobserved "rental" quality and lower unobserved "owner" quality. These findings imply that imputed rents and rent-to-price measures that do not control for selection are biased.

These three facts quantify an intuitive relationship between a property's attributes, its prices in the rental and owner-occupied sectors, and its propensity to be rented. For instance, gross yields that decline with the value of the underlying land are consistent with a user-cost decomposition where maintenance costs ${ }^{1}$ increase primarily with the value of the structure. Meanwhile, selection based on the value of the structure even as gross yields increase with physical value is consistent with a theory where agency problems increase maintenance costs in the rental sector relative to the owner-occupied sector; particularly for larger properties and for properties that are more detached. Similarly, maintenance of some unobservable attributes, like a nice kitchen or a jacuzzi may be particularly hard to contract upon for landlords and thus increase the likelihood that properties with those characteristics appear in the owneroccupied sector, whereas other unobservable attributes, like features of the property's vicinity or qualities of its view, may be value enhancing but do not pose contracting problems and therefore do not affect selection. As we discuss below, the enumerated facts above may also be consistent with other, nonmaintenance cost explanations.

\footnotetext{
${ }^{1}$ Throughout we refer to the costs of upkeep and care of a structure costs as maintenance costs. They are the costs required to keep a property at constant quality.
} 
1.1. Relation to the Literature. An extensive household tenure-choice literature studies demand-side selection into homeownership. This literature studies who chooses to own houses and how household tenure choice interacts with decisions such as savings decisions. For example, see Rosen (1979), Goodman (1988), Kan (2000), or Campbell and Cocco (2007). In contrast, in this article, we study supply-side selection; what aspects of housing units explain why some units are more likely to end up in the owner-occupied sector, whereas others are more likely to end up in the rental sector.

Glaeser and Shapiro (2003) and Amior and Halket (2014) observe that there is a striking difference in the homeownership rates of single versus multifamily housing units throughout the United States. This leads the former to hypothesize that "homeownership is particularly correlated with housing structure." Using more detailed data from England, we show that not only is ownership correlated with structure but also it is correlated with many other physical attributes.

What explains these correlations? One hypothesis is that there are sectoral differences in the costs of capital or in operating costs. For instance, it has long been suggested that the housing market contracts may be constrained by tenure-dependent information frictions. A literature going back to Sweeney (1974) and Henderson and Ioannides (1983) has argued that contracting frictions in the rental sector result in higher maintenance costs and less upkeep and investment. Because of monitoring costs, tenants under-invest in maintenance resulting in a higher depreciation rate. In this literature, it is assumed but often unstated that these differential costs are likely to be correlated with the physical characteristics of the property. As a result, a housing unit with higher rental-specific maintenance costs, or for which rental contracting frictions are greater, is more likely to be found in the owner-occupied sector.

Another possible explanation is that landlords with lower costs of capital (perhaps due to tax wedges) sort into physically smaller houses but not into high-value locations based on property size-related advantages. We are unaware of any existing theories that explicitly provide this exact prediction. Coulson and Fisher (2014) argue that there may be some endogenous differences in ownership structure (and thus perhaps financing costs) based on variation in maintenance technologies across ownership structures and the physical size of the building.

Empirical support for these theories has been scant. Linneman (1985) notes that the "efficiency" of landlord provided housing services is an important factor determining ownership rates. Casas-Arce and Saiz (2010) examine how different jurisdictions' legal systems and propensities to enforce contracts affect ownership propensities. Hanson (2012) looks at how the mortgage interest tax deduction interacts with home sizes to affect ownership rates in the United States. Hilber (2005) examines neighborhood externality risks in the American Housing Survey (AHS) and finds that they are negatively correlated with homeownership. Harding et al. (2000) find that homeowners who are more likely to default on their mortgage may undermaintain their house.

In the corporate finance literature, studies of selection due to various contracting or tax frictions and the effects of selection on the distribution of observed returns are common (e.g., Prabhala, 2008). In the housing literature, there are no studies that control for supply-side selection when estimating hedonic rent and price functions. The closest perhaps is Heston and Nakamura (2009) who show that owner-occupied housing units are $15 \%$ more valuable than observably equivalent rentals in several small markets. We are the first to: (a) estimate a selection model of hedonic housing prices and rents for a large housing market, (b) estimate the importance of unobserved quality in this market, and (c) analyze the implications of this model for sector-specific user costs. Furthermore, we use repeated cross sections sampled from periods of both housing price decline and boom in England and find that the estimated relationship between physical attributes, selection, and rent-to-price remains very stable.

In Section 6, we use the selection model results to estimate rental and owner-occupied user costs. Moreover, if we assume that a single risk-adjusted discount rate prices all housing as in Epple et al. (2020), then differential rent-to-price ratios across properties, must be due either to differing expectations or to differences in the costs of renting out the property. We 
argue that expectations, given rents and prices, should not systematically affect selection into renting. This enables us to use our selection model results to estimate the potential size of the moral hazard problem described above. These additional findings rely on fairly strong assumptions. We cannot rule out other potential mechanisms such as variation in the effective discount rates that price various types of housing. Our data do not include measures of maintenance or other variables that would allow us to test one mechanism against another.

Our findings have important implications for macro models of the housing market. In the United Kingdom and the United States, more than $60 \%$ of households tie up a large part of their financial portfolio in a single, risky, illiquid asset, and housing. Why is this the case? Why do not financial and rental housing markets provide contracts that enable households to enjoy the consumption flow from a rented, three bedroom, detached, $120 \mathrm{~m}^{2}$ property in the suburbs while enjoying the dividend flows and potential capital gains of the wider financial market?

Numerous theoretical explanations have been proposed to explain the high market share of homeownership, including insurance motives, tax considerations, a "warm glow" from housing, and a variety of rental sector contracting problems. For instance, Chambers et al. (2009a, 2009b), Chen (2010), and Oswald (2019) incorporate higher maintenance costs for rentals and a limited supply of "high-value" rentals into their models. We show that selection due to unobservables can simultaneously explain both higher maintenance costs and the limited supply of physically valuable rentals. Our estimates imply that differential maintenance costs are large, consistent with the calibrations in the macro models.

Finally, accounting for unobserved quality can explain two curious features in the raw data. First, several studies have attempted to measure whether rental properties have higher observed maintenance costs. Viewed together, the results appear inconclusive and differences between rental and owner-occupied maintenance expenditures in national accounts data are small. Galster (1983) estimates that owner-occupiers occupy better properties and better maintain them. Shilling et al. (1991) estimate hedonic models of rents and prices in a single parish in Louisiana and find that rentals depreciate faster. Malpezzi et al. (1987) estimate hedonic models of rents and prices from the AHS and find that rents decline evenly with age, whereas prices decline at a declining rate. However, Gatzlaff et al. (1998) find limited evidence of differential maintenance by comparing appreciation rates of rentals and owneroccupied housing units.

Using the assumptions in Subsection 6.3.3, our selection findings can rationalize these mixed results. Because of selection on unobservables, cross-tenure comparisons of maintenance costs do not necessarily reveal evidence of differential maintenance costs. Properties with higher maintenance costs select into owner-occupancy. Not properly accounting for selection on unobservables leads to biased measures of maintenance cost differences. Under some assumptions about interest rates and capital gains, our estimates suggest (as an upper bound) that rental property maintenance costs for large rental properties can be as much as $40 \%$ higher. This evidence of large differential maintenance costs is consistent with the theory of contracting frictions outlined above.

Second, several studies (see Verbrugge, 2008; Heston and Nakamura, 2009, Garner and Verbrugge, 2009; Verbrugge and Poole, 2010; Landvoigt et al., 2015, and Epple et al., 2020) using U.S. data have found that rent-to-price ratios decline with property prices. If we do not control for selection, we also find that rent-to-price ratios decline with property prices. Taken at face value, this implies that the more expensive a property is, the lower is its predicted rent-to-price ratio. As ownership rates are (unconditionally) increasing in dwelling prices, this could lead one to the curious conclusion that households tend to own ${ }^{2}$ homes that have low rent-to-price ratios. However, we show in Subsection 5.3.1 that this counterintutive finding

\footnotetext{
2 Throughout we use "households owning a home" (or equivalent) interchangeably with owner-occupancy. We are never referring to a households' propensity to own a home it does not occupy as its primary residence (e.g., investment or vacation homes).
} 
stems from failure to control for selection. After controlling for selection, households tend to own housing units whose physical characteristics imply high rent-to-price ratios; in accord with the intuition that, all else equal, households choose ownership when it is inexpensive relative to renting.

Sections 2 and 3 introduce the model and data, respectively. Section 4 explains our estimation procedure. Section 5 discusses the empirical results for property values, rents, and ownership probabilities. Section 6 discusses implications of our results for user costs and maintenance.

\section{MODEL}

A property has observed characteristics $z \in \mathbf{R}^{n}$ and unobserved characteristics $\varepsilon \in \mathbf{R}^{\mathbf{3}}$. Observed characteristics include location, size, dwelling type, and a number of additional property characteristics (number of rooms, quality, etc.) detailed in Subsection 4.1. We assume that the value of unobserved characteristics is completely captured by a vector of three factors that affect rental-sector rents, owner-sector prices, and selection into sector. The model allows for differential valuation of characteristics across sectors, imperfect correlation between sector allocation and prices and rents, and unobserved factors that affect sector allocation but not prices or rents.

2.1. Rent and Price Equations. If a dwelling unit is in the rental sector, its rent is observed. Let $\log$ annual rent be given by

$$
\ln R\left(z, \varepsilon_{r}\right)=\alpha z+\varepsilon_{r}
$$

This is a log linear approximation to the true hedonic rent function. The parameter vector $\alpha$ measures the percentage impact of observed characteristics on rents and $\varepsilon_{r}$ captures the impact of unobserved characteristics on rents.

Similarly, if a dwelling unit is in the owner-occupied sector, its value is observed. Let the log value in the owner-occupied sector be

$$
\ln \pi_{o}\left(z, \varepsilon_{o}\right)=\beta z+\varepsilon_{o}
$$

This is a $\log$ linear approximation to the hedonic price function. The parameter vector $\beta$ captures the percentage impact of observed characteristics on prices in the owner-occupied sector. The variable $\varepsilon_{o}$ captures the impact of unobservable characteristics on owner-sector prices. We allow $\varepsilon_{o}$ and $\varepsilon_{r}$ to be correlated.

If a property is in the rental sector, its value is not observed. Nevertheless, let the log value of a dwelling in the rental sector be

$$
\ln \pi_{r}\left(z, \varepsilon_{o}-\varepsilon_{s}\right)=(\beta-\gamma) z+\varepsilon_{o}-\varepsilon_{s}
$$

The parameter vector $\gamma$ captures the net loss or gain in willingness-to-pay by a landlord relative to an owner-occupier. Positive elements of $\gamma$ correspond to characteristics that generate a net loss in the rental sector and negative elements correspond to characteristics that reflect a net gain. Similarly, $\varepsilon_{o}-\varepsilon_{s}$ reflects how unobservable factors affect the net gain or loss in relative values. We discuss the relationship between rental sector prices and rents in Subsection 6.1 .

2.2. Allocation of Properties to Sectors. In equilibrium, a property is owned by the agent (landlord or owner-occupier) who has the highest value. Thus, for each property, choices of landlords and owner-occupiers determine which sector the property is in. If a property is in the rental sector, we observe rent $R$ but not value $\pi_{r}$. If it is in the owner-sector, we observe 
value $\pi_{o}$ but not the implicit utility of occupancy. This is the censoring problem in our application.

Mathematically, a housing unit is observed in the owner-occupied sector if

$$
\ln \pi_{o}\left(z, \varepsilon_{o}\right) \geq \ln \pi_{r}\left(z, \varepsilon_{o}-\varepsilon_{S}\right) .
$$

That is, if

$$
\gamma z+\varepsilon_{s} \geq 0
$$

The values $\pi_{o}$ and $\pi_{r}$ are conditioned on sector. They measure willingness to pay of buyers in each sector. The unconditional price of a property is the price of the property in the market where it is most valuable. That is,

$$
P(z, \varepsilon)=\max _{\{\text {own }, \text { rent }\}}\left\{\pi_{o}\left(z, \varepsilon_{o}\right), \pi_{r}\left(z, \varepsilon_{o}-\varepsilon_{S}\right)\right\}
$$

The parameters of the value and rent functions may vary over time. We leave their dependence on $t$ implicit.

Let $\varepsilon=\left(\varepsilon_{r}, \varepsilon_{o}, \varepsilon_{s}\right)$. Under the assumption that $\varepsilon \sim N(0, \Sigma)$ independent of $z$, this is a standard Type 5 Tobit model (Amemiya, 1985). In the Type 5 Tobit model, as long as the variables in $z$ are linearly independent, the normalized parameters $(\alpha, \beta, \tilde{\gamma})$ and $\left(\sigma_{r r}, \sigma_{o o}, \widetilde{\sigma}_{r s}, \widetilde{\sigma}_{o s}\right)$ are identified where $\widetilde{\gamma}=\frac{\gamma}{\sqrt{\sigma_{s s}}}, \tilde{\sigma}_{r s}=\frac{\sigma_{r s}}{\sqrt{\sigma_{s s}}}$, and $\widetilde{\sigma}_{o s}=\frac{\sigma_{o s}}{\sqrt{\sigma_{s s}}}$. We use the notation $\sigma_{i j}$ to denote the $(i, j)$ element of the covariance matrix $\Sigma$. As in all discrete choice models, the parameter $\sigma_{s s}$ is not identified because sector choice is a binary choice. Also, $\sigma_{r o}$ is not identified because $\pi_{o}$ and $R$ are never simultaneously observed.

For most of our analysis, these normalizations play no role. Our quantitative results on selection, rents, and prices are invariant to the normalization. In Section 6, these normalizations do play a role. Values of the parameters $\left(\sigma_{r o}, \sigma_{s s}\right)$ affect our estimates of user costs and contracting costs. We discuss identification of these additional parameters in Subsection 6.2.

The model has several important features. First, the value of unobserved characteristics in the owner-occupied sector is not restricted to be perfectly correlated with the value in the rental sector. Second, the impact of unobserved characteristics on selection is not restricted to be perfectly correlated with owner-occupied prices nor with rents. Third, the correlation of $\varepsilon_{r}$ and $\varepsilon_{s}$ may differ from the correlation between $\varepsilon_{o}$ and $\varepsilon_{s}$. Economically, selection into sectors may be differentially related to unobservables that have high value in the rental sector, $\varepsilon_{r}$, versus unobservables that have high value in the owner-sector, $\varepsilon_{o}$.

In the next two sections, we discuss the data and estimation results. Then in Section 6, after discussing estimates of $\left(\pi_{o}, R, \pi_{r}\right)$ and the selection of properties into the two sectors, we discuss the extent to which the estimates are consistent with how various components of user costs may vary across properties and across the two sectors.

\section{DATA}

We use data from the "secure access" version of waves 2011-2014 of the English Housing Survey (EHS). The secure access version of the EHS contains detailed information on a large sample of properties including information on postcode, value, rent, and a large set of property characteristics. The sample is not a simple random sample but is constructed as follows:

The EHS uses a complex multistage methodology. Each wave comprises two surveys that are then combined to produce two samples. Each sample is constructed using data from surveys from multiple waves. In each wave, the EHS team conducted a "household survey" and a "physical survey." For example, to construct the 2011 wave, the EHS team sampled approximately 17,500 households in the financial year 2008/2009 (April 2008-March 2009). These 
households were drawn from the list of addresses held by Royal Mail. At each sampled address, one dwelling was sampled. At each dwelling, one household was sampled.

Respondents from this selection (approximately 17,000) comprised the household interview sample. The EHS team then chose a subsample of these dwellings (approximately 8,000 in 2008/2009), including vacant ones, and performed a physical inspection. This is called the "physical survey." The subsample was constructed from the 17,500 by including all social housing ${ }^{3}$ addresses and taking a subsample of private addresses. Private rental properties were oversampled. Finally, to construct the final "housing stock" sample, the EHS team combined data from two physical surveys. For instance, the housing stock sample in the 2011 wave is composed of the physical surveys from 2008/2009 and 2009/2010. Weighting for the final sample is based on this two-year sampling window.

We focus discussion on the 2011 wave of the EHS. Although we also analyze the 2012, 2013, and 2014 waves, these later waves have some limitations. In the later waves, property prices were top-coded at $£ 1,000,000$. Also, due to budget cuts, the later waves used smaller samples and collected information on a smaller range of topics. Despite these limitations, our results are robust across waves. Because the samples in each wave use data from a two year span, the samples overlap. For instance, the samples in the 2011 and 2012 waves both contain the same data collected in 2009/2010 as part of their samples.

Owner-occupied property values recorded in the survey were obtained in one of two ways. For $82.7 \%$ of properties, owners self-reported an estimate of the current market value. For the remainder of owner-occupied properties, a professional surveyor valued the property onsite. Rental sector rents were self-reported by tenants.

For each dwelling, the secure access version of the EHS reports the full postcode. ${ }^{4} \mathrm{We}$ match each postcode with its geographic coordinates using the 2013 Office for National Statistics's Postcode Directory. Because postcodes can change over time, a few postcodes are unmatched. In 2014, one owner-occupied property out of 5,184 is unmatched and two private rentals out of 2,683 are unmatched. In 2011, none are unmatched. The numbers of unmatched properties for other waves are similar. For these unmatched properties, we impute coordinates using the mean geographic coordinates of all postcodes sharing the same postcode district (postcodes are grouped geographically and the first three to four characters of a seven to eight character postcode are its postcode district). For each property, we then convert its geographic coordinates to polar coordinates $(d, \theta)$ centered around Trafalgar square. That is, for each property we compute $d$, the Euclidean distance from Trafalgar Square, and $\theta$, the bearing or angular distance from due east measured in radians. That is, $\theta=0$ is east, $\theta=0.5 \pi$ is south, etc.

Our analysis focuses on the subsample of dwellings within $140 \mathrm{~km}$ of Trafalgar Square in London. We label this region "Greater London." It is worth noting that this $140 \mathrm{~km}$ circle extends beyond the London "travel to work area" (TTWA) defined by UK statistical authorities. The TTWA, by definition, includes only $75 \%$ of the economically active population. We extend it to ensure that our sample of properties in less dense areas is large enough while still retaining a reasonable commute to London and thus arguably a single economic market. For example, a train ride from Ipswich, at the outer edge of our Greater London region, to London Liverpool St Station takes a little over an hour. ${ }^{5}$ Our results are robust to alternative definitions of Greater London and are robust to including the full sample for all of England. We use the Greater London subsample because, in our view, it constitutes a single economic market, and because distance from London has such a large effect, that focusing on London facilitates visual interpretation of our results using graphs.

\footnotetext{
${ }^{3}$ Social housing units are public housing units that are owned or regulated by the government. They consist of Local Authority (LA) provided housing and housing provided by Registered Social Landlords (RSL). RSL's are nonprofit organizations that provide low-cost housing. Rents for all social housing units are regulated by the government and highly subsidized.

${ }^{4}$ The average size of a postcode in the greater London area (our focus, as explained below) is $0.09 \mathrm{~km}^{2}$.

${ }^{5}$ http://ojp.nationalrail.co.uk/service/timesandfares/IPS/LST/tomorrow/0715/dep
} 
TABLE 1

MARKET SHARES: GREATER LONDON AND ENGLAND (\%)

\begin{tabular}{lcccc}
\hline Region & EHS Wave & Owner-Occupied & Private Rented & Social Housing \\
\hline London & 2011 & 66.6 & 15.7 & 17.7 \\
& 2012 & 65.3 & 17.0 & 17.8 \\
& 2013 & 63.1 & 18.7 & 18.1 \\
England & 2014 & 62.4 & 19.5 & 18.2 \\
& 2011 & 67.9 & 14.3 & 17.8 \\
& 2012 & 67.0 & 15.1 & 17.9 \\
& 2013 & 65.3 & 16.4 & 18.3 \\
\hline
\end{tabular}

Notes: Market shares are computed using sampling weights for each wave. London refers to the Greater London sample area. The 2011 wave uses data from April 2008 to March 2010. The 2012 wave uses data from April 2009 to March 2011. The 2013 wave uses data from April 2010 to March 2012. The 2014 wave uses data from April 2011 to March 2013. Social housing includes Local Authority provided housing and housing provided by Registered Social Landlords.

TABLE 2

MARKET SHARE BY DISTANCE: GREATER LONDON 2011 WAVE (\%)

\begin{tabular}{lccc}
\hline Distance & Owner-Occupied & Private Rented & Social Housing \\
\hline Less than $10 \mathrm{~km}$ & 37.9 & 23.7 & 38.4 \\
$10-20 \mathrm{~km}$ & 61.6 & 19.8 & 18.6 \\
$20-30 \mathrm{~km}$ & 69.8 & 13.5 & 16.8 \\
$30-50 \mathrm{~km}$ & 71.4 & 13.1 & 15.5 \\
More than $50 \mathrm{~km}$ & 72.9 & 13.4 & 13.7 \\
\hline
\end{tabular}

NotEs: Market shares are calculated using data and sampling weights from the 2011 wave of the EHS. The 2011 wave uses data from April 2008 to March 2010. Social housing includes Local Authority provided housing and housing provided by Registered Social Landlords.

We present summary statistics for the owner-occupied, private rental, and social housing sectors. However, when we estimate the model, we restrict the analysis to private sector housing. In the private sector, investors may buy and sell properties freely and prices are determined by the market. In the social sector, supply is largely determined by political forces, not by the choices of investors. In addition, prices in this sector are subsidized and highly regulated.

Table 1 displays the overall market shares of owner-occupied housing, private rentals, and publicly assisted housing in England and Greater London. In England in Wave 2011 (2008-2010), 67.9\% of housing units were owner-occupied units, whereas $14.3 \%$ were private rentals and $17.8 \%$ were social housing. The market shares in Greater London are similar, $66.6 \%, 15.7 \%$, and $17.7 \%$, respectively. Greater London has slightly more private rentals and fewer owner-occupiers. By Wave 2014 (2011-2013), the share of private rentals has increased by 3 percentage points at the expense of owner-occupancy.

Table 2 shows how market shares vary with distance from the center of London. Within 10 $\mathrm{km}$ of the center, the owner-occupied share is $37.9 \%$, whereas the private rented and social housing shares are $23.7 \%$ and $38.4 \%$, respectively. The owner-occupied share increases with distance. More than $50 \mathrm{~km}$ from the center, the owner-occupied share is $72.9 \%$, whereas the rental and social housing shares decline to $13.4 \%$ and $13.7 \%$, respectively. We will see that these patterns with respect to distance do not persist after controlling for structural characteristics.

Tables 3 and 4 show how market shares vary with size and dwelling type. Large properties are much more likely to be owner-occupied; $90.1 \%$ of properties larger than $100 \mathrm{~m}^{2}$ are owner-occupied versus only $33.1 \%$ for properties less than $50 \mathrm{~m}^{2}$. Similarly, semidetached and detached houses and bungalows are much more likely to be in the owner-occupied sector, whereas converted flats and dwellings in multiunit structures are more likely to be in 
TABLE 3

MARKET SHARE BY DWELLING SIZE: GREATER LONDON 2011 WAVE (\%)

\begin{tabular}{lccc}
\hline Dwelling Size & Owner-Occupied & Private Rented & Social Housing \\
\hline Less than $50 \mathrm{~m}^{2}$ & 33.1 & 27.4 & 39.5 \\
$50-60 \mathrm{~m}^{2}$ & 47.5 & 25.4 & 27.2 \\
$60-80 \mathrm{~m}^{2}$ & 60.3 & 17.1 & 22.6 \\
$80-100 \mathrm{~m}^{2}$ & 74.6 & 12.6 & 12.8 \\
More than $100 \mathrm{~m}^{2}$ & 90.1 & 7.24 & 2.63 \\
\hline
\end{tabular}

Notes: Market shares are calculated using data and sampling weights from the 2011 wave of the EHS. The 2011 wave uses data from April 2008 to March 2010. Social housing includes Local Authority provided housing and housing provided by Registered Social Landlords.

TABLE 4

MARKET SHARE BY DWELLING TYPE: GREATER LONDON 2011 WAVE (\%)

\begin{tabular}{lccc}
\hline Dwelling Type & Owner-Occupied & Private Rented & Social Housing \\
\hline Semidetached & 73.9 & 13.0 & 13.7 \\
Detached & 94.4 & 5.0 & 0.40 \\
Bungalow & 76.8 & 5.0 & 18.3 \\
Converted flat & 39.3 & 48.5 & 15.2 \\
Low rise & 32.2 & 26.7 & 38.4 \\
High rise & 20.7 & 19.7 & 48.1 \\
\hline
\end{tabular}

Notes: Market shares are calculated using data and sampling weights from the 2011 wave of the EHS. The 2011 wave uses data from April 2008 to March 2010. The semidetached category includes "End Terrace" and "Mid Terrace." Social housing includes Local Authority provided housing and housing provided by Registered Social Landlords.

the rental sector. And $73.9 \%, 94.4 \%$, and $76.8 \%$ of the former dwelling types are owneroccupied, whereas only $39.3 \%, 32.3 \%$, and $20.7 \%$ of the latter types are owner-occupied. As with the previous literature, we find that homeownership is particularly correlated with structure. We will see that these patterns hold up even after controlling for location and other property characteristics.

There are substantial differences in other variables across sectors as well. ${ }^{6}$ Owner-occupied properties are bigger and have more rooms. They have rear plots that are nearly twice as large as rental properties $\left(8.2 \mathrm{vs} .15 .4 \mathrm{~m}^{2}\right)$. They are more likely to have three or more bedrooms $(74 \%$ vs. $39 \%)$, two or more bathrooms (30\% vs. $14 \%)$, and two or more living rooms ( $47 \%$ vs. $18 \%$ ). Owner-occupied properties also have slightly higher investments in energy efficiency. Thirty-one percent of owner-occupied properties have cavity loft insulation versus $15 \%$ of rental properties. Eighty percent have high degrees of double glazing (more than $80 \%$ of windows double glazed) versus $67 \%$ of rentals. Rentals do have slightly higher energy efficiency scores but that could be because they are smaller; it is cheaper to heat and light a small property. Finally, owner-occupied properties are more likely to have access to off-street parking $(77 \%$ vs. $47 \%)$ and more likely to have no litter in the neighborhood ( $82 \%$ vs. $69 \%)$.

\section{ESTIMATION}

As noted previously, the model from Section 2 is a Type 5 Tobit model. The estimating equations are Equations (1) and (2) and

$$
\ln \pi_{o}-\ln \pi_{r}=\gamma \mathbf{z}+\varepsilon_{\mathbf{s}} .
$$

As discussed in Amemiya (1985), Lee and Trost (1978), and Willis and Rosen (1979), the two pairs of equations, (1) and (7) and (2) and (7), can be estimated separately at the cost of ef-

\footnotetext{
${ }^{6}$ See Table A.1 in the online Supplemental Appendix for summary statistics by sector for the other main variables that are used in our empirical analysis below.
} 

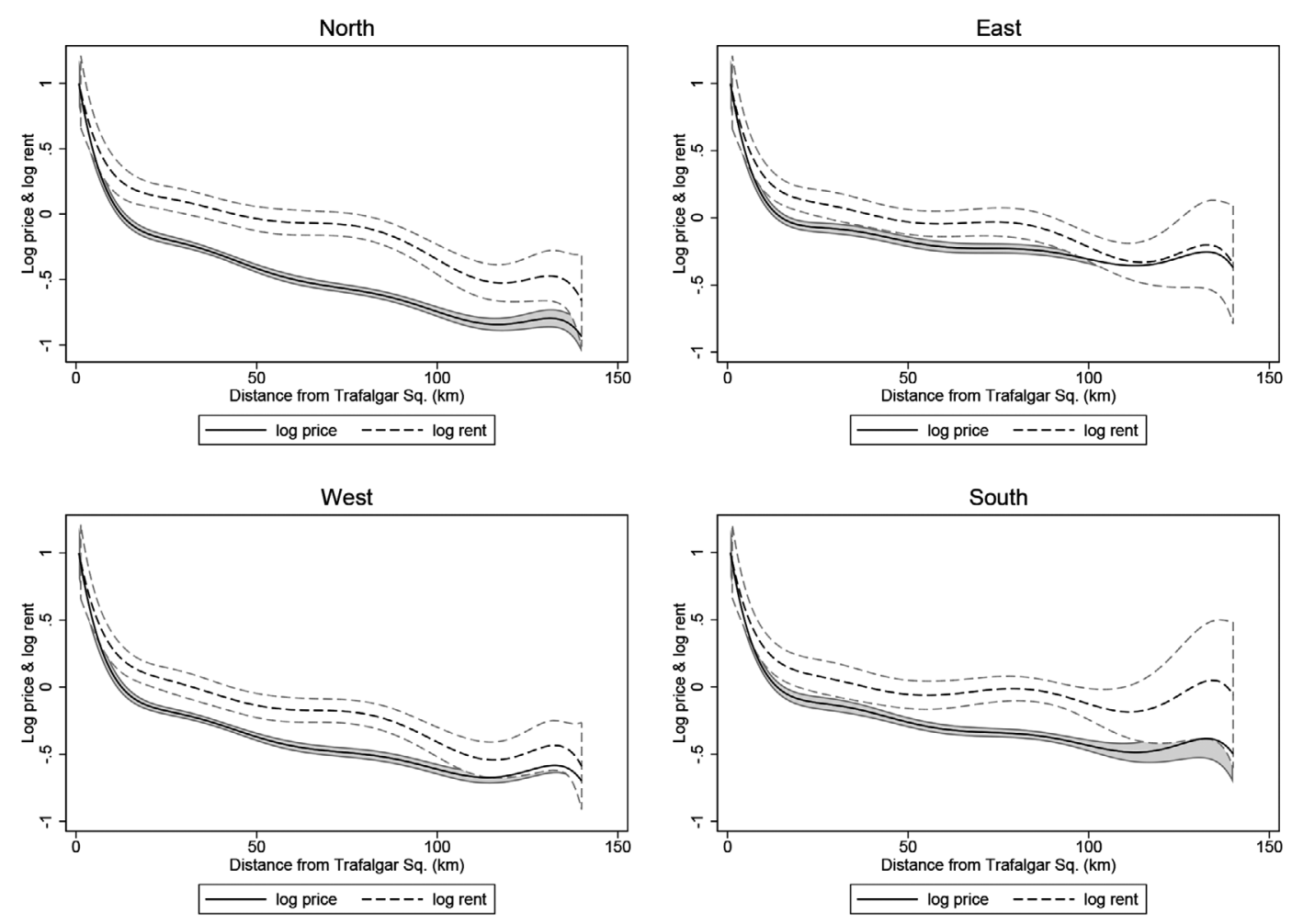

Note: Log rents and prices have been normalized to equal 1 at the center of London.

FIGURE 1

RELATIVE RENTS AND PRICES VERSUS LOCATION

ficiency. Each pair of equations is a standard Type 2 Tobit model, and therefore, the parameters in each pair can be estimated either using maximum likelihood estimation or Heckman's two-step procedure. Due to computational constraints in the secure data laboratory, we chose to estimate the two pairs of equations separately using maximum likelihood estimation. In our case, separate estimation produces statistically indistinguishable estimates of the common parameters $\gamma$.

Using our data, the two-step Heckman procedure fails to produce reliable estimates because the inverse Mills ratio is nearly collinear with the other regressors. In contrast, maximum likelihood estimates remain robust because the score of the log likelihood function exploits cross-equation restrictions.

In Subsection 4.1, we discuss Model 1, our baseline specification. This is our preferred specification based on model fit and parsimony. Results for Model 1 are discussed in Section 5, reported in Table 5 and displayed in Figures 1-7.

In Appendix A.1, we discuss several alternative specifications (Models 2-9) that test sensitivity to additional property characteristics and to exclusion restriction assumptions. In Models 2-5, we add a large number of additional variables to the baseline specification to test whether the results are robust. Except for results with respect to number of rooms discussed in Subsection 5.2.2 below, the main results remain unchanged. In Models 6-9, we tested several models with exclusion restrictions. The main results are unchanged. Summary results from these robustness exercises are presented in Appendix A.1 and complete results are presented in the online Supplemental Appendix. 
TABLE 5

ESTIMATION RESULTS - BASELINE MODEL

\begin{tabular}{|c|c|c|c|}
\hline & $\begin{array}{l}\text { Owner-Occupied Sector } \\
\text { Log-Value }\end{array}$ & $\begin{array}{l}\text { Rental Sector } \\
\text { Log-Rent }\end{array}$ & Selection Equation \\
\hline SAP05 & $\begin{array}{r}-0.002 \\
(0.001)\end{array}$ & $\begin{array}{r}-0.001 \\
(0.002)\end{array}$ & $\begin{array}{r}-0.007 \\
(0.002)\end{array}$ \\
\hline Cavity, insulation & $\begin{array}{c}0.053 \\
(0.023)\end{array}$ & $\begin{array}{c}0.110 \\
(0.060)\end{array}$ & $\begin{array}{c}0.377 \\
(0.093)\end{array}$ \\
\hline Cavity, no insulation & $\begin{array}{c}0.040 \\
(0.027)\end{array}$ & $\begin{array}{c}-0.037 \\
(0.077)\end{array}$ & $\begin{array}{c}0.020 \\
(0.115)\end{array}$ \\
\hline Heating age: $3-12$ years & $\begin{array}{c}-0.031 \\
(0.015)\end{array}$ & $\begin{array}{c}-0.087 \\
(0.041)\end{array}$ & $\begin{array}{c}-0.173 \\
(0.069)\end{array}$ \\
\hline Heating age: $12+$ years & $\begin{array}{r}-0.064 \\
(0.017)\end{array}$ & $\begin{array}{c}-0.115 \\
(0.046)\end{array}$ & $\begin{array}{r}-0.226 \\
(0.072)\end{array}$ \\
\hline Double glazed $(80 \%+)$ & $\begin{array}{r}-0.039 \\
(0.017)\end{array}$ & $\begin{array}{c}0.052 \\
(0.038)\end{array}$ & $\begin{array}{c}0.184 \\
(0.068)\end{array}$ \\
\hline Street parking & $\begin{array}{c}-0.018 \\
(0.026)\end{array}$ & $\begin{array}{c}-0.058 \\
(0.049)\end{array}$ & $\begin{array}{c}0.018 \\
(0.087)\end{array}$ \\
\hline Off-street parking & $\begin{array}{c}0.120 \\
(0.024)\end{array}$ & $\begin{array}{c}0.112 \\
(0.046)\end{array}$ & $\begin{array}{c}0.344 \\
(0.078)\end{array}$ \\
\hline Minor litter & $\begin{array}{c}-0.092 \\
(0.016)\end{array}$ & $\begin{array}{r}-0.149 \\
(0.037)\end{array}$ & $\begin{array}{c}-0.258 \\
(0.062)\end{array}$ \\
\hline Major litter & $\begin{array}{c}-0.138 \\
(0.054)\end{array}$ & $\begin{array}{c}-0.128 \\
(0.129)\end{array}$ & $\begin{array}{c}-0.146 \\
(0.218)\end{array}$ \\
\hline Rear plot depth & $\begin{array}{c}0.004 \\
(0.001)\end{array}$ & $\begin{array}{c}0.008 \\
(0.002)\end{array}$ & $\begin{array}{c}0.013 \\
(0.003)\end{array}$ \\
\hline Self-reported value & $\begin{array}{r}-0.094 \\
(0.015)\end{array}$ & & \\
\hline Market rent & & $\begin{array}{c}0.654 \\
(0.081)\end{array}$ & \\
\hline Partly furnished & & $\begin{array}{c}0.007 \\
(0.032)\end{array}$ & \\
\hline Unfurnished & & $\begin{array}{c}-0.037 \\
(0.027)\end{array}$ & \\
\hline$\rho_{i s}=\operatorname{corr}\left(\varepsilon_{i}, \varepsilon_{s}\right)$ & $\begin{array}{c}0.667 \\
(0.083)\end{array}$ & $\begin{array}{c}0.951 \\
(0.012)\end{array}$ & \\
\hline$\sigma_{i i}$ & $\begin{array}{c}0.090 \\
(0.0088)\end{array}$ & $\begin{array}{c}0.386 \\
(0.0525)\end{array}$ & \\
\hline$N$ & 4059 & 4059 & \\
\hline $\begin{array}{l}\text { log likelihood } \\
R^{2}\end{array}$ & $\begin{array}{c}-3.52 \mathrm{e}+06 \\
0.650\end{array}$ & $\begin{array}{c}-3.26 \mathrm{e}+06 \\
0.433\end{array}$ & \\
\hline
\end{tabular}

Notes: The table displays weighted (using EHS sampling weights) maximum likelihood estimates of Type II Tobit model parameter values estimated using data from the 2011 wave of the EHS. The model includes the variables listed in the table, dummy variables for quarter and dwelling age, and nonparametric functions of size, distance from London, and direction. For the nonparametric functions, we use Chebyshev polynomials in distance and in size and Fourier series in angular direction. The number of terms in the series were chosen to minimize the Bayes information criteria (BIC). The selected model includes third-order polynomials in size (in square meters), seventh-order polynomials in distance (in kilometers), and Fourier series up to order 3. Polynomial and Fourier series coefficients and selected other variables are omitted from the table for concision. Column (1) displays owner-occupied sector results for the model of log value. Column (2) displays rental sector results for the model of log rent. Column (3) displays results from the selection equation. Standard errors are in parentheses.

4.1. Baseline Specification: Model 1. In the baseline specification, $z$ includes nonparametric functions of location and size and indicator variables for dwelling type. We describe the nonparametric functions in more detail below. In addition, the specification includes dwelling age, parking availability, litter in the local neighborhood, rear plot depth, and several measures of energy efficiency. ${ }^{7}$ For our baseline specification, we do not include the number of

\footnotetext{
${ }^{7}$ Each property has an energy efficiency rating calculated by the surveyor using the Standard Assessment Procedure (SAP05 or SAP09). This rating is based on an estimate of each dwelling's energy cost per square meter. It takes
} 

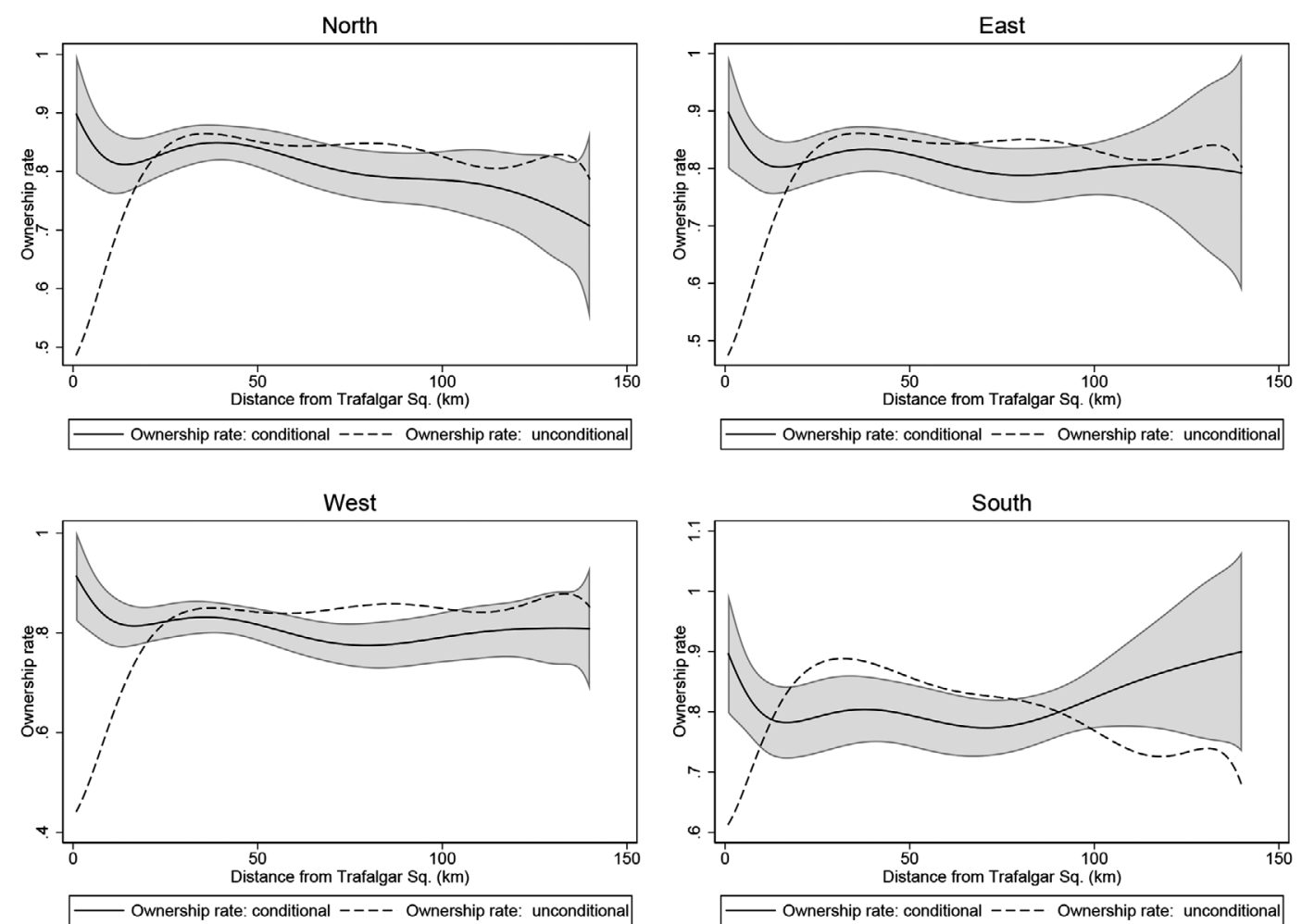

FiguRE 2

OWNERSHIP VERSUS LOCATION

bedrooms separately from dwelling size because number of bedrooms is highly collinear with property size. We discuss the impact of bedrooms further in Subsection 5.2.2. For owneroccupied properties, we also include an indicator for whether the property price is selfreported or not. For rentals, we include measures of whether the rental was furnished and an indicator for whether the rental was self-reported to be at market rent. ${ }^{8}$

Dwelling size is measured in square meters. As discussed in Section 3, location coordinates are measured in polar coordinates, distance $d$ from Trafalgar square, and bearing. The baseline model includes third-order Chebyshev polynomials in size, seventh-order Chebyshev polynomials in distance, and third-order Fourier series in bearing. The model also includes interactions between the distance terms and the bearing terms. We considered models with higher orders and additional interactions between distance and bearing. Our baseline specification was chosen as the specification that minimizes the Bayes information criterion (BIC). Adding additional polynomials terms added variability to estimates of the effects of size, distance, and bearing without substantially changing other results.

The nonparametric functions of location are important to capture complex spatial patterns in prices, rents, and selection. Although they do not capture all such patterns, because the sample is finite, they do allow the model to be as flexible as possible given the sample size. The distance variables capture the impact of distance from London on property prices and rents

account of the cost of space and water heating, ventilation, and lighting. We also include indicators for the age of the heating system and extent of insulation and double glazing.

${ }^{8}$ In the sample, $55 \%$ of rentals are unfurnished and $7 \%$ are not let by private, arms-length landlords. For the former properties, rents are slightly lower because furniture is not provided. For the latter, rents are lower because the landlord is a friend, relative, or employer. We capture these additional observable rental contract elements through indicators that affect rent but not selection. 
2011 wave (west)
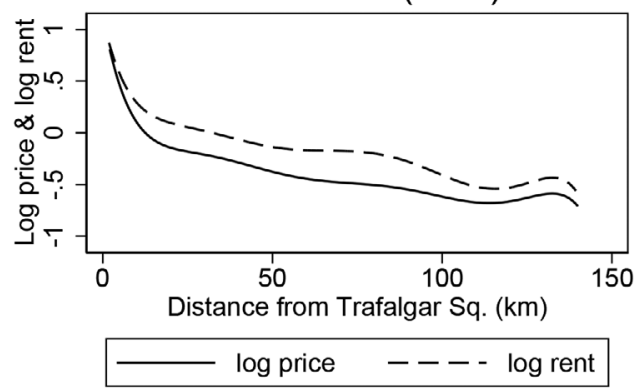

2013 wave (west)

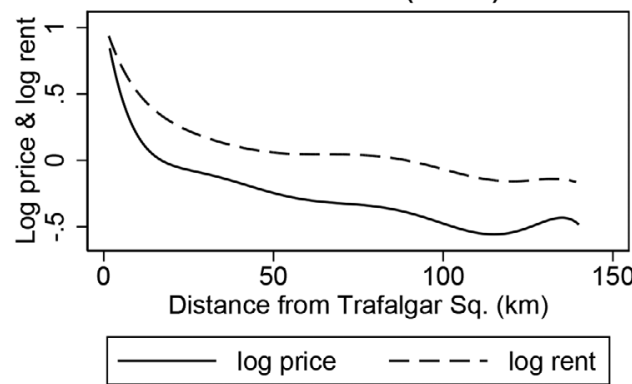

2012 wave (west)
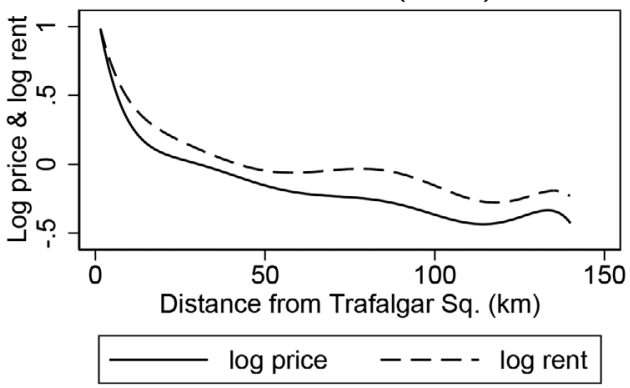

2014 wave (west)

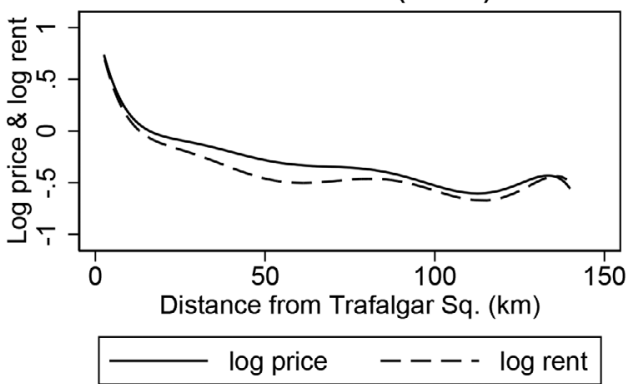

Note: Log rents and prices have been normalized to equal 1 at the center of London. Confidence bands have been omitted in this figure to improve the readability. They are qualitatively similar to the ones displayed in Figure 1.

FIGURE 3

RELATIVE RENTS AND PRICES VERSUS LOCATION: TIME VARIATION
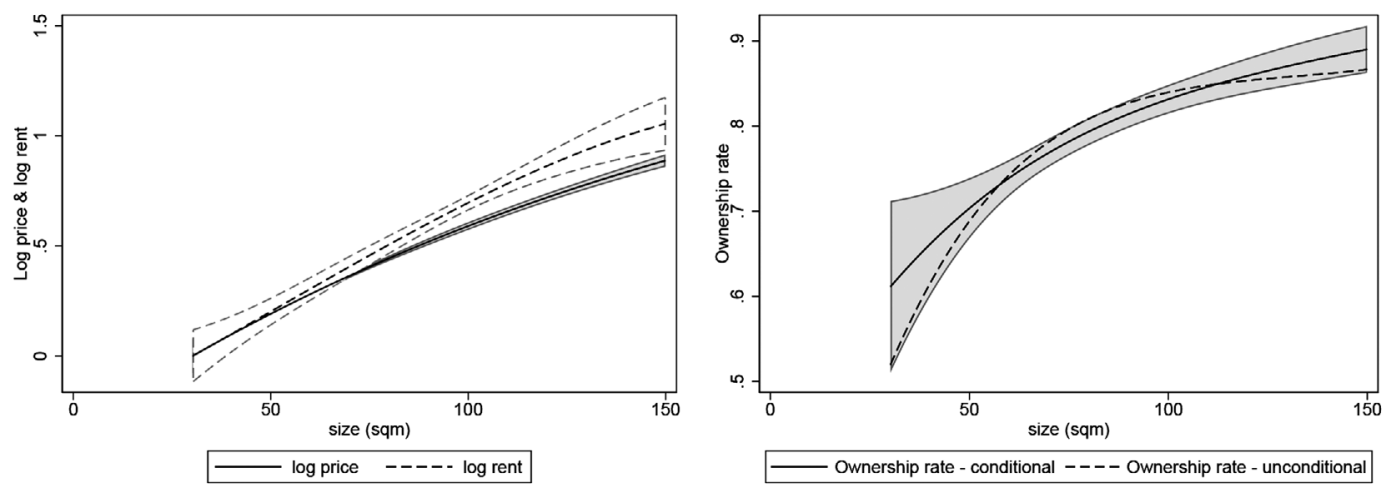

Note: Log rents and prices have been normalized to equal 0 at $40 \mathrm{~m}^{2}$.

FIGURE 4

RENTS, PRICES, AND OWNERSHIP VERSUS SIZE

and on selection into the owner-occupied sector. The bearing variable $\theta$ captures variation in outcomes that depends on the direction of travel when moving away from the center. For example, as seen in Figure 1, the rate of decline of prices with distance is higher heading north or west than east or south. Interactions between distance and direction capture spatial patterns that might be caused by the location of motorways or rail lines, employment or shopping subcenters, or more generally local amenities or disamenities. For example, prices are higher near motorways and rail lines and near employment subcenters. 

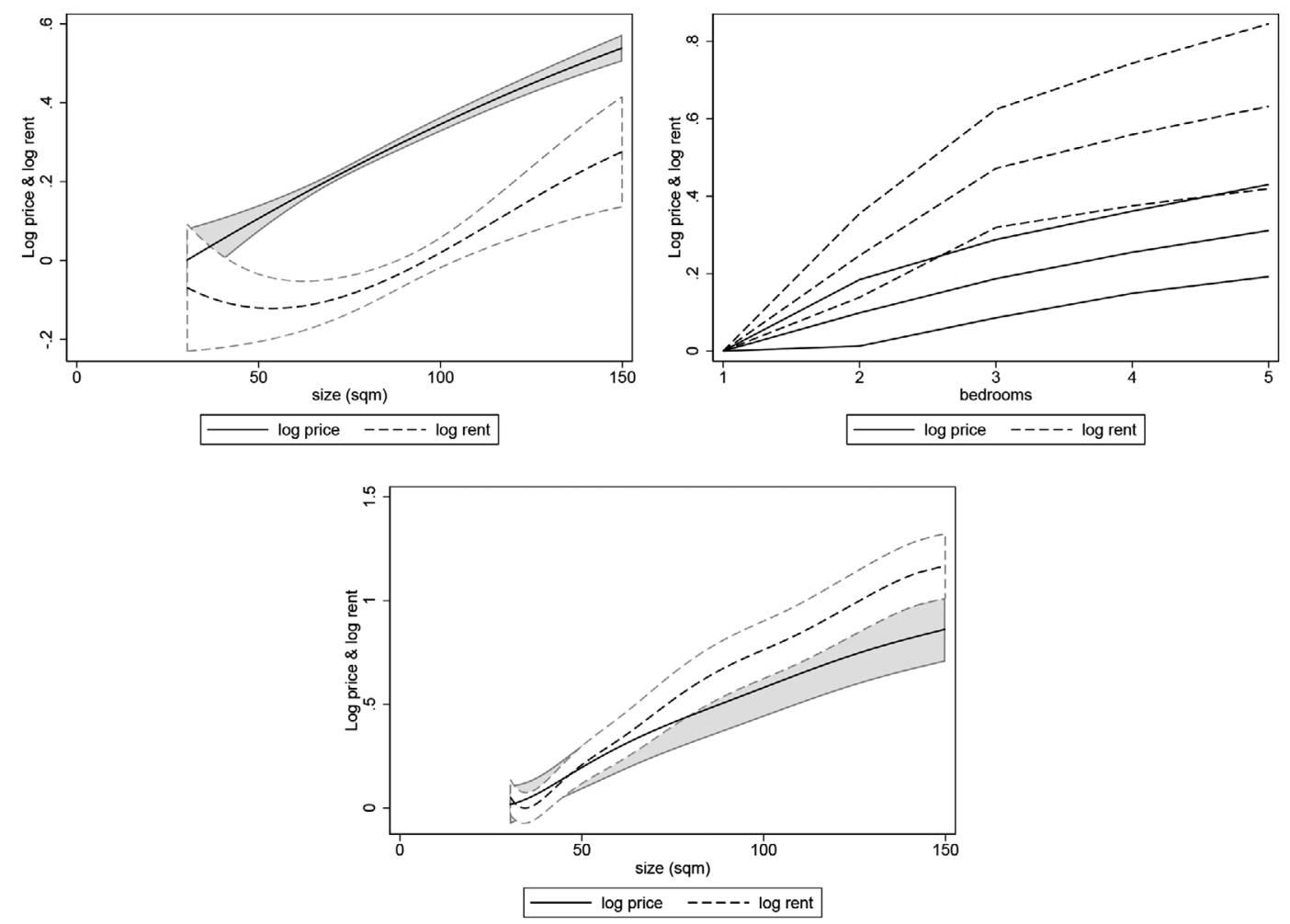

Notes: The top left panel shows how predicted prices and rent vary with size holding number of rooms fixed. The top right panel shows predicted prices and rents versus bedrooms holding size and number of other rooms fixed. The bottom panel shows predicted prices and rents versus size and E(rooms|size). Log rents and prices have been normalized to equal 0 at $40 \mathrm{~m}^{2}$ and 1 bedroom, respectively.

Figure 5

RELATIVE RENTS AND PRICES VERSUS SIZE, BEDROOMS, AND BEDROOMS + SIZE

\section{RESULTS}

In this section, we present results that show how property characteristics affect property values, rents, and ownership rates. Alongside these results, we discuss their economic implications. We focus our discussion on results for the most important locational, the nonparametric functions of distance and bearing, and the most important structural characteristics, property size, and dwelling type. We do not report parameter estimates for these characteristics because the parameter values have no natural interpretation. Instead, for each characteristic, we plot predicted values, rents, and ownership rates. In each case, we discuss how property values and rents change with property characteristics and compare that to how ownership rates vary with property characteristics. This comparison allows us to draw out the economic implications of our results. As will become clear, the results for structural characteristics have qualitatively similar patterns, whereas those for location are importantly different. In Section 6, we draw out the implications for estimates of the user costs of owner-occupied and rental housing.

Finally, in this section, we discuss the results on unobserved property characteristics. We show that selection on unobservables is important and that controlling for unobserved quality has important impacts on predictions for how property values, rents, and ownership rates vary with observable locational and structural characteristics.

The estimated effects of the remaining characteristics are detailed in Table 5. For the most part, the parameter estimates are economically plausible and consistent with our main results. 

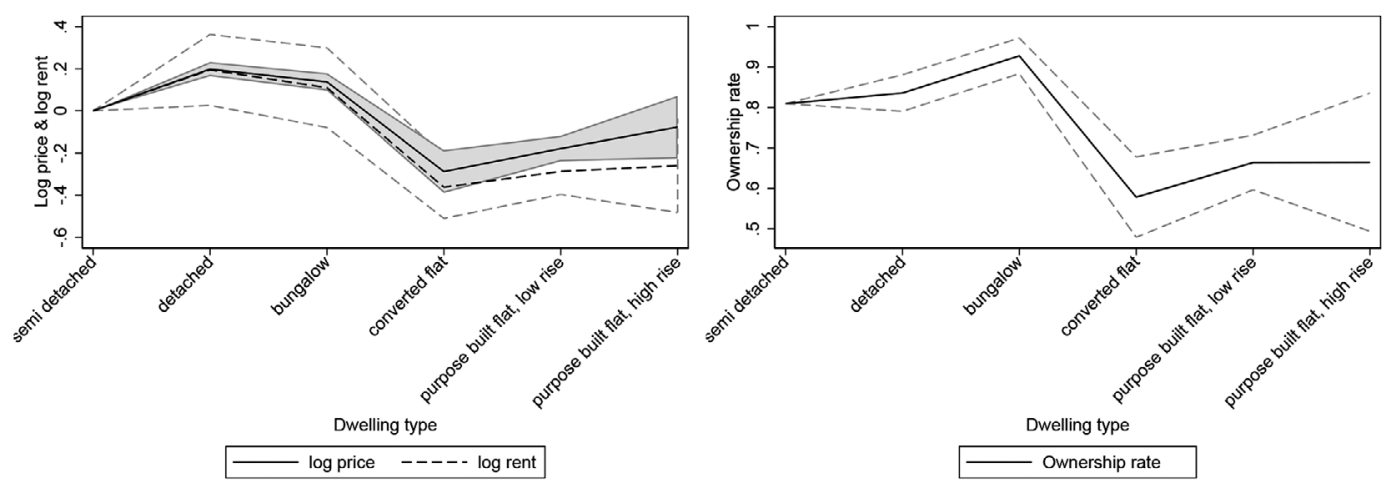

Note: Log rents and prices have been normalized to equal 0 for semidetached housing.

FIGURE 6

RENT, PRICE, AND OWNERSHIP VERSUS DWELLING TYPE
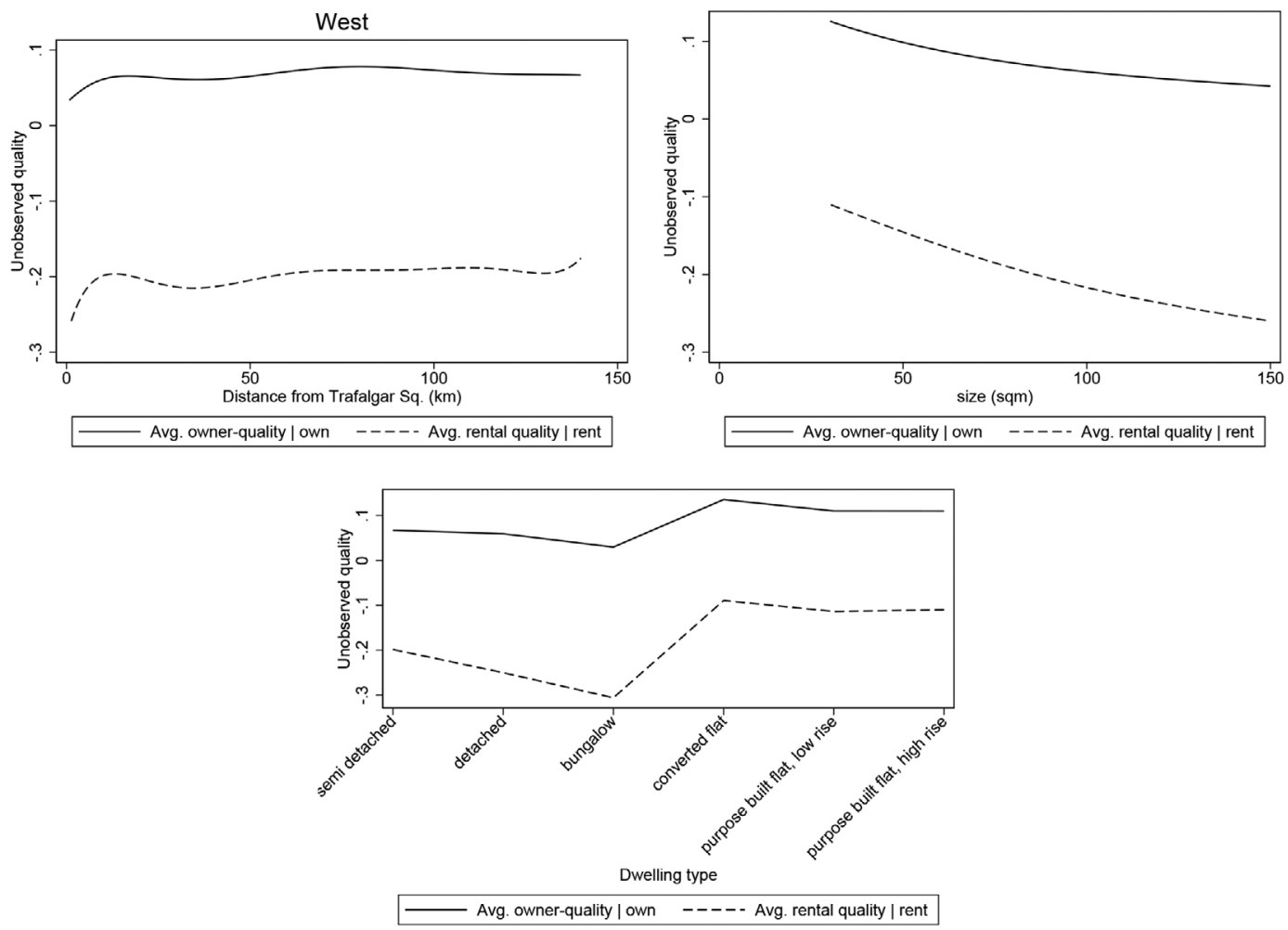

Figure 7

UNOBSERVED QUALITY

Rents increase with structural characteristics faster than prices, in the same way that rents increase faster with respect to property size. At the same time, ownership rates increase despite increasing rent-to-price ratios. Better insulation or a newer heating system raises rents more than values and increases the probability of being in the owner-occupied sector. Off-street parking raises rents and values more or less equally and also increases the probability of being in the owner-occupied sector. Minor litter lowers rents more than values and lowers the 
probability of being in the owner-occupied sector. Rents increase faster than values with rear plot depth, whereas ownership rates increase.

A few parameter estimates are either insignificant or counterintuitive. More energyefficient properties have lower prices, lower rents, and are more likely to be rental properties. The size of these effects is small. Properties with more double glazing are more likely to be owner-occupied but have $3.9 \%$ lower values.

5.1. Location. Figure 1 shows how prices and rents decline with distance conditional on direction. Pointwise confidence bands are illustrated with shaded areas. There is one panel for each angle of the compass. In all cases, property values and rents decline dramatically as one moves away from the center and values decline faster than rents. Moving an otherwise identical owner-occupied property North from the center for a distance of $10 \mathrm{~km}$ implies that its value will fall by about $63 \%$. For the same change in distance moving to the North, rents decline by $45 \%$ relative to the central rental property. ${ }^{9}$ In both sectors, the hedonic functions flatten out appreciably at distances greater than $15 \mathrm{~km}$. Regardless of direction, the qualitative pattern is the same; however, values in the owner-occupied sector decline more when going North.

These results are obtained without controlling for overall lot size. Our data do not include information on overall lot size, though we have included a measure of the rear plot depth. If anything, this likely biases the estimated slopes toward 0 . Lot sizes are probably larger further away from the city center where land is cheaper.

Figure 2 shows the estimated relationship between distance and the owner-occupancy rate when moving away from central London. Again, there is one panel for each direction of the compass. The "unconditional" lines plot the estimated relationship between distance and ownership when no other correlates are included. The "conditional" lines plot the relationship with distance holding other characteristics fixed. ${ }^{10}$ As in Table 2, the unconditional line shows that owner-occupancy is far more prevalent $20 \mathrm{~km}$ outside of London than inside the city center. However, the conditional line shows that, once other housing unit characteristics are controlled for, distance essentially plays no role in selection into owner-occupancy. Owneroccupancy as a function of distance is essentially flat at around $80-81 \%$.

In summary, both rents and prices fall with distance. Rents relative to prices rise with distance but distant housing units are not more likely to be found in the rental sector. Why then do not investors in properties far from the center convert more properties into rental units? It must be that it is not profitable to do so. Why might this be the case? Here, we propose some theoretical explanations based on our discussion in Subsection 6.1.

One possible explanation is that even though rents rise relative to values as distance grows, maintenance costs relative to rents also rise as the value of the location falls. This point is best illustrated by thinking about the value of a property as being composed of the value of land and the value of built structure. Structure requires more maintenance than land. So, maintenance costs are increasing in the proportion of the value that is structural. Given that the value of land decreases quickly as distance increases and the other characteristics of the property are being held constant in these plots, the proportion of value that is structural increases with distance. A second possible explanation is that vacancy costs in the rental sector are higher further out because the rental markets there are thinner, resulting in longer expected vacancy durations and higher equilibrium rents. A third possible explanation is that properties close to the city center had higher expected capital gains during the period of our study. In any case, no matter the cause, our results showing no selection with respect

\footnotetext{
${ }^{9}$ This is calculated as percentage change between central price and price at $10 \mathrm{~km}$, where log price is equal to 0 in the first panel of Figure 1, that is, $\% \Delta=100 \frac{\exp (0)-\exp (1)}{\exp (1)}=-63 \%$.

${ }^{10}$ The figure shows deviation of the predicted ownership rate from the sample average as distance varies. To achieve this, other characteristics $z_{2}$ are held fixed so that $\widehat{\gamma}_{2} z_{2}=\Phi^{-1}(0.809)-\widehat{\gamma}_{1} \bar{z}_{1}$ where $\bar{z}_{1}$ is the vector of mean values of the distance polynomials and 0.809 is the sample average ownership rate.
} 
to distance indicate that the relative value of a property on the two sectors $\left(\pi_{r}\right.$ vs. $\left.\pi_{o}\right)$ is not affected by distance; the higher costs or lower expected capital gains of suburban properties are capitalized into rents.

Some limited evidence on these points can be obtained by studying changes in the hedonic functions over time. Figure 3 shows estimated hedonic prices and rents versus distance for all four waves of the EHS, 2011-2014. The functions become slightly steeper over time and the rent-to-price ratio is unstable. In the most recent wave, 2014, the rental function is in some areas slightly steeper with respect to distance than the price function, the opposite of the earlier waves. These facts suggest that perhaps (a) expected capital gains are location-dependent and (b) the relative difference in expected capital gains across locations may change at a fairly high frequency. Though we do not have good data on household expectations by location, it is at least true that ex post capital gains have varied widely over this same time period. For example, our calculations using UK Land Registry data show that, from 2009 to 2014, property prices within $10 \mathrm{~km}$ of London increased $42 \%$, whereas prices further out increased only by $22 \% .{ }^{11}$

\subsection{Structure.}

5.2.1. Size. Figure 4 (left panel) shows how rents and prices change with respect to the total floor space of the property. Compared to a baseline size of $40 \mathrm{~m}^{2}$, an otherwise identical $100 \mathrm{~m}^{2}$ owner-occupied property will have a $73 \%$ higher value, whereas the same increase in size implies a $101 \%$ increase in rent in the rental sector. As a result, rent-to-price ratios increase with size. The right panel of Figure 4 shows how size affects the probability of being owner-occupied. Again, we compare the results from the selection model to an "unconditional" probit of ownership on size. The effects are dramatic. Unlike location and like dwelling type, size is hugely important for explaining variation in selection, even after controlling for other covariates. The market share of the owner-occupied sector increases from about $70 \%$ for properties $50 \mathrm{~m}^{2}$ in size to almost $80-90 \%$ for properties larger than $100 \mathrm{~m}^{2}$. In summary, the rent-to-price ratio increases with size, whereas the allocation of properties to the rental sector decreases with size.

5.2.2. Rooms versus size. Model 2 adds bedrooms, living rooms, bathrooms, kitchens, fireplaces, attic, basement, and balcony to the baseline model. Detailed results from this model are discussed in Appendix A.1 and in the online Supplementary Appendix. Figure 5 plots results from Model 2, showing how our results on size are affected by adding these measures of numbers of rooms. The top left panel of Figure 5 plots the effects of size on log rents and log prices holding number of rooms fixed. The top right panel plots the effects of number of bedrooms on log rents and log prices holding size fixed. The bottom panel shows the effects of size plus E(rooms|size). That is, it shows the "total" effect of size on predicted log rents and log prices, including both the direct effect (top left panel) and the indirect effect (effect due to changes in expected number of rooms as size varies).

In contrast to Figure 4, the top left panel of Figure 5 shows that when number of rooms is held fixed, size hardly affects rents at all for properties less than $80 \mathrm{~m}^{2}$. As a result, for small properties, when number of rooms is held fixed, prices increase with size faster than rents. However, for larger properties, rents increase with size faster than values. Looking at the top right panel, rents increase much faster with number of bedrooms than values. Overall then, the impact of size and bedrooms on prices and rents is more nuanced than that illustrated in Figure 4.

However, number of rooms and size are highly correlated in the data, especially for smaller properties. This is common sense. It is difficult to have three bedrooms, two living rooms, or a big kitchen with only $60 \mathrm{~m}^{2}$ of floor space. Taking this into account, the bottom panel

${ }^{11}$ Further details on these calculations are available from the authors upon request. 
of Figure 5 shows the total effects of size including the direct effects and the indirect effects due to changes in the various room indicators. These results are statistically and economically similar to those from the base specification plotted in Figure 4. One can see that including rooms in the model does not change the qualitative predictions of the model.

5.2.3. Dwelling type. Figure 6 shows how prices, rents, and ownership vary with dwelling type. Both rents and values are higher for more "detached" properties (detached properties, semidetached properties, and bungalows). Based on the point estimates, the rent-to-price ratio is highest for semidetached and detached properties, declines by $2.8 \%$ for bungalows, $7.4 \%$ for converted flats, $10.8 \%$ for low rise flats, and $18.3 \%$ for high-rise flats. Of these, the decline for low-rise flats is statistically significant at the $10 \%$ level. The evidence is somewhat weak due to large standard errors, but all is consistent with more detached properties having higher rent to price ratios.

At the same time, more detached properties are more likely to be owner-occupied. These results are stable over waves. ${ }^{12}$ As with size above and in contrast to location, higher values and rents are positively correlated with owner-occupancy. In contrast to location, the conditional relationship between dwelling type and predicted ownership is qualitatively similar to the unconditional relationship. The unconditional relationship is detailed in Table 4. Excluding the social housing sector, $95 \%$ of detached, $85 \%$ of semidetached properties, and $93.9 \%$ of bungalows are in the owner-occupied sector while dwellings in multiunit structures (converted flats, low rise, and high rise) have ownership rates that vary between $44.8 \%$ and $54.7 \%$. Physical features are important determinants of selection into the owner-occupied sector. Figure 6 shows that conditional on location and other characteristics, the average predicted ownership rate is between $80 \%$ and $90 \%$ for semidetached, detached, and bungalows and falls to around $60 \%$ for dwellings in multiunit structures.

The pattern is similar to the stylized fact documented in Glaeser and Shapiro (2003) that, in the United States, housing units in multiunit structures are extremely likely to be rented ( $85.9 \%$ in their study), whereas single-unit housing is very likely to be owned $(85.5 \%$ in their study). Unconditional ownership rates do not vary quite as much in England across structure types. Conditioning narrows the difference still further.

In summary, as with property size, we find that the rent-to-price ratio is higher for properties with high-valued characteristics (detached houses) but the allocation of detached houses to the rental sector is lower. One caveat to these results is the following. In England, property ownership predominantly takes one of two forms, freehold or leasehold. Freehold ownership is ownership in perpetuity. Leasehold ownership is ownership of a long lease (e.g., 75 or 99 years). ${ }^{13}$ It is clear that property prices should depend on the freehold or leasehold status of the property. Unfortunately, the EHS only records information on the type of holding for owner-occupied properties. For the Greater London subsample, leaseholds comprise only $11 \%$ of owner-occupied properties. In addition, holding type is highly correlated with dwelling type. In the EHS sample, fewer than $23 \%$ of flats are freeholds, whereas nearly $94 \%$ of detached houses are freeholds. Giglio et al. (2015) find that leasehold flats sell for a noticeable duration-dependent discount compared to otherwise identical freeholds. So, some of the decline in prices that is captured by dwelling type may, in fact, be due to the higher prevalence of leaseholds for flats. However, they also find that the type of holding does not affect rents. So, the decline in rent-to-price ratios for flats is likely understated by omitting holding type. When an indicator for ownership type is included in the property price equation, the parameter estimate is $0.107(0.042)$. Freehold status increases property prices nearly $10.7 \%$ relative to leasehold status. The estimates in Figure 6 are robust to including an indicator for leasehold in our estimation of Equation (2).

\footnotetext{
12 Results from other waves on dwelling type and size as well as other unreported results are available upon request.

${ }^{13}$ A third form of ownership, "commonhold," exists but is almost never used due to legal uncertainties.
} 
TABLE 6

ROBUSTNESS OF SELECTION RESULTS

\begin{tabular}{lccccc}
\hline & Model 1 & Model 2 & Model 3 & Model 4 & Model 5 \\
\hline$\rho_{o s}=\operatorname{corr}\left(\eta_{o}, \eta_{s}\right)$ & 0.667 & 0.691 & 0.703 & 0.697 & 0.701 \\
& $(0.083)$ & $(0.068)$ & $(0.067)$ & $(0.066)$ & $(0.065)$ \\
$\rho_{r s}=\operatorname{corr}\left(\eta_{r}, \eta_{s}\right)$ & 0.951 & 0.951 & 0.950 & 0.951 & 0.950 \\
& $(0.012)$ & $(0.012)$ & $0.013)$ & $(0.013)$ & $(0.012)$ \\
$\sigma_{o o}$ & 0.090 & $(0.008)$ & $(0.008)$ & $(0.008)$ & 0.076 \\
& $(0.009)$ & 0.337 & 0.324 & 0.324 & $(0.008)$ \\
$\sigma_{r r}$ & 0.386 & $(0.042)$ & $(0.040)$ & $(0.040)$ & 0.324 \\
& $(0.0525)$ & & $(0.040)$ \\
\hline
\end{tabular}

Notes: The table displays weighted (using EHS sampling weights) selected results from five model specifications. Each successive model encompasses the previous model. Model 1 is the baseline model results presented above. Model 2 adds indicators for two bedrooms, three bedrooms, four bedrooms, five or more bedrooms, two bathrooms, three or more bathrooms, one living room, two or more living rooms, one or more big kitchens, fireplaces, an attic, a balcony and a basement. Model 3 adds the principal components of property quality, as described in the text. Model 4 adds the first set of principal components for neighborhood quality. Model 5 adds the second set of neighborhood quality principal components.

5.3. Unobserved Quality. Table 5 reports estimates of the model's error correlations. We estimate $\rho_{r s}=0.95$ and $\rho_{o s}=0.67$ where $\rho_{r s}$ and $\rho_{o s}$ are the correlations between $\varepsilon_{s}$ and $\varepsilon_{r}$ and $\varepsilon_{o}$, respectively. These estimates imply that likely rental sector properties (low $\varepsilon_{s}$ ) have low unobserved rental quality $\left(\varepsilon_{r}\right)$ and that likely owner-occupied properties (high $\varepsilon_{s}$ ) have high unobserved owner-occupied quality $\left(\varepsilon_{o}\right)$. As seen in Table 6 , these results are robust. Adding a large range of additional variables to the baseline model, as in Models 2-5, has no impact on the correlation estimates. In addition, Models 6-9, reported in the Supplementary Appendix, produce virtually identical estimates. We conclude that a strong and robust pattern of selection on unobservables affects properties in the London housing market.

Using these estimates, in Figure 7, we show how the predicted average unobserved owneroccupied quality $\left(\varepsilon_{o}\right)$ and rental quality $\left(\varepsilon_{r}\right)$ vary with distance from London, size, and dwelling type. The top left panel in the figure shows that average owner-quality $\left(\varepsilon_{o}\right)$ conditional on being owner-occupied is positive but does not vary with location. It also shows that average rental-quality $\left(\varepsilon_{r}\right)$ conditional on being a rental is negative and also does not vary with location. The results imply that an average owner-occupied property has a $5 \%$ higher value than a randomly selected observationally identical property, whereas an average rental property has $20 \%$ lower rent than a randomly selected observationally identical property.

The top right panel shows similar estimates of unobserved quality as a function of size. In both sectors, unobserved quality decreases with size since owner-occupancy rates increase with size. Because the rental sector error correlation is larger, unobserved rental quality declines faster. Large rental housing units are likely to be of much lower unobserved rental quality. The average rental quality difference between a $50 \mathrm{~m}^{2}$ rental property and a $100 \mathrm{~m}^{2}$ rental property is almost $5 \%$ compared with an approximate $2.5 \%$ difference in similar sized owneroccupied properties. Finally, the lower panel shows similar results for unobserved quality versus dwelling type. More detached properties have lower unobserved quality and the decline is stronger for rental sector properties.

One explanation for these results is the following: Some amenities affect users' enjoyment of a property but also have high maintenance costs. Such amenities raise rents, are negatively correlated with selection into the rental sector, and have a smaller net impact on property prices (due to the capitalization of high maintenance costs). Examples of such amenities could be a jacuzzi, nice countertops, and cabinets in the kitchen or a built-in stereo system. Other amenities could affect both prices and rents but have little effect on selection, perhaps because they raise no maintenance concerns. Examples could include aspects of the property's layout, architecture, or view. 
Other possible explanations include differential expected capital gains, costs of capital, or differential vacancy costs. It is logically possible that properties with high unobserved rental quality also had expected rental sector capital gains that were low relative to owner-occupied capital gains. This would be counterintuitive and is unlikely since the option value of switching sectors is part of the expected rental sector gain. Furthermore, given that our findings are robust over several waves, it would imply that these expectations persisted for a number of years. Under rational expectations, this would imply a growing gap in values.

It is also possible that properties with high unobserved rental quality also incur higher rental sector capital costs; banks may have information about unobserved rental quality and judge such properties to be higher risk or riskier landlords may sort into properties with higher unobserved rental quality. However, we are not aware of any literature or evidence providing support for this possibility. Finally, it is possible that markets for properties with high unobserved rental quality are thin and therefore have high expected vacancy costs.

Our unobserved quality results offer a partial explanation for a puzzle in the housing literature; how to explain high homeownership rates. Many models of homeownership and housing demand include a preference for owning (i.e., a "warm glow" from owning, e.g., see Iacoviello and Pavan, 2013 or Kiyotaki et al., 2011). Such a preference for owning is often required to generate high homeownership rates. Our results show that estimating homeownership demand using only observables would indeed find a preference for owning because rentals have lower average unobserved quality and the difference in average unobserved quality is increasing in the ownership probability.

5.3.1. Bias in imputed rents and/or prices. The estimation results imply that hedonic estimates of rents and prices that do not control for selection are biased. We find that these biases are statistically and economically significant. Moreover, removing the bias helps explain a common and puzzling finding in the literature.

To illustrate the bias, we reestimate $\alpha$ and $\beta$ without controlling for selection. We then predict $\log$ rents and $\log$ values using both our original estimates and the biased estimates and plot the differences (the biases). Figure 8 shows the biases in imputed log rent for owneroccupied properties and in imputed value for rental properties. The figure shows how these biases vary with location, size, and dwelling type. The first panel shows that the bias in imputed rents is $25 \%$ on average (here in westerly direction, but robust to other directions). The bias does not vary with location. However, the bias does vary significantly with property characteristics. The top right panel shows that it is less than $20 \%$ for small rental properties and increases to close to $30 \%$ for very large properties. The bottom panel shows that the bias in imputed rents is more than $20 \%$ for semidetached and more than $25 \%$ for detached properties. The bias in imputed values moves in the opposite direction. The average bias is less than $10 \%$ in this case. The bias is high for small properties and low for large properties. It is low for detached properties and high for flats.

These results have important implications for statistical authorities and for real estate professionals. Imputed rents are used by statistical authorities to measures output in the owneroccupied sector for the national accounts and to account for housing in price indices. They are also considered by tax authorities when considering taxation of implicit income from owneroccupied properties. Imputed values of rental properties can also be used to value rental properties that have not recently transacted.

As a second illustration of the importance of the bias, the left panel in Figure 9 plots the biased predictions of rent-to-price ratios against the biased predictions of log price for both rentals and owner-occupied properties. It also plots the homeownership rate versus the predicted log price. One can see in the figure that homeownership rates increase with predicted $\log$ price. At the same time, the biased predictions of the rent-to-price ratio decline with the price of the home. This is a common finding. Verbrugge (2008), Heston and Nakamura (2009), Verbrugge and Poole (2010), Bracke (2015), and Epple et al. (2020) all find that rent-to-price ratios decline with prices and Landvoigt et al. (2015) estimate that housing service flows rise 

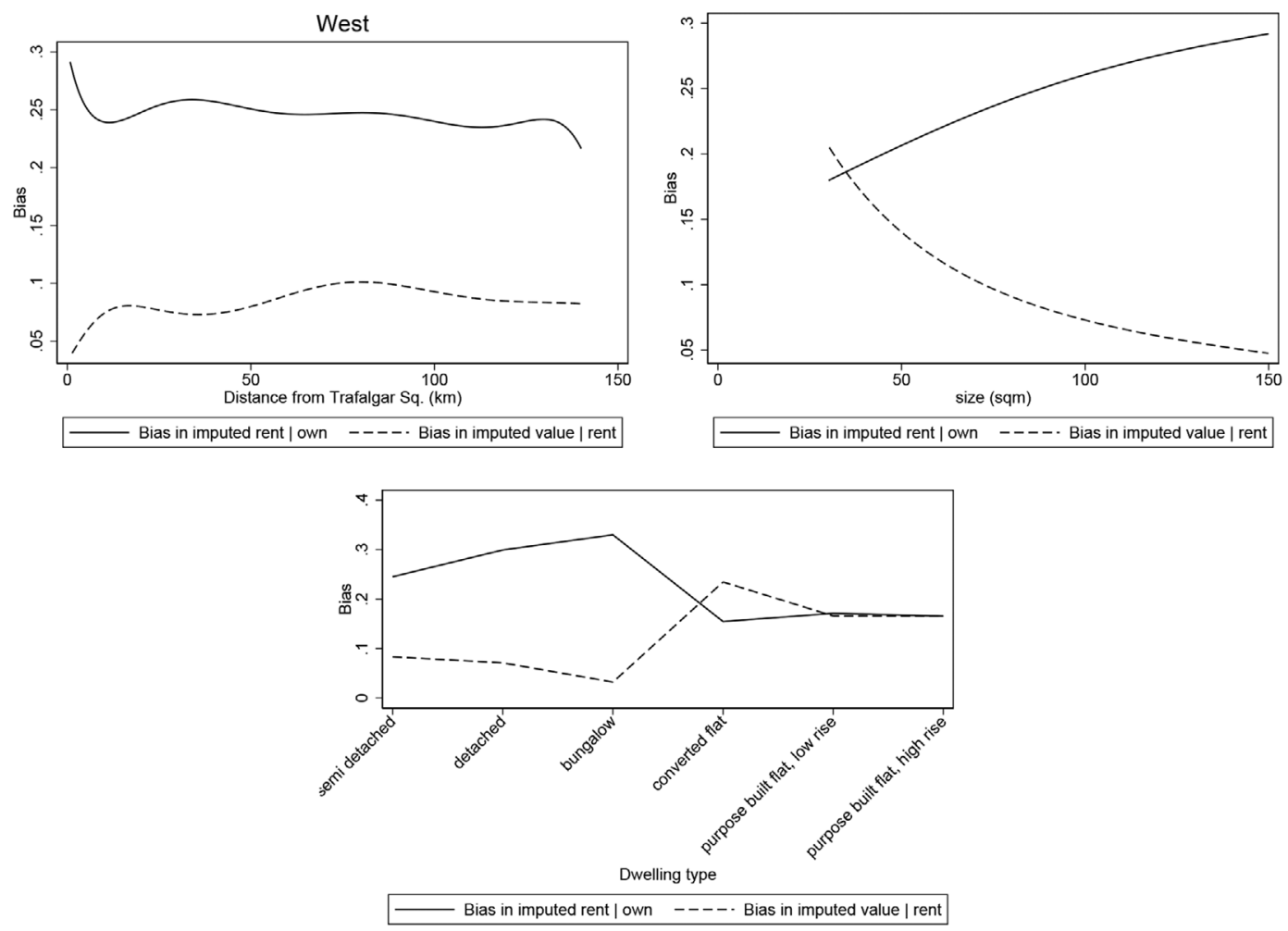

FIGURE 8

BIAS IN IMPUTED RENT
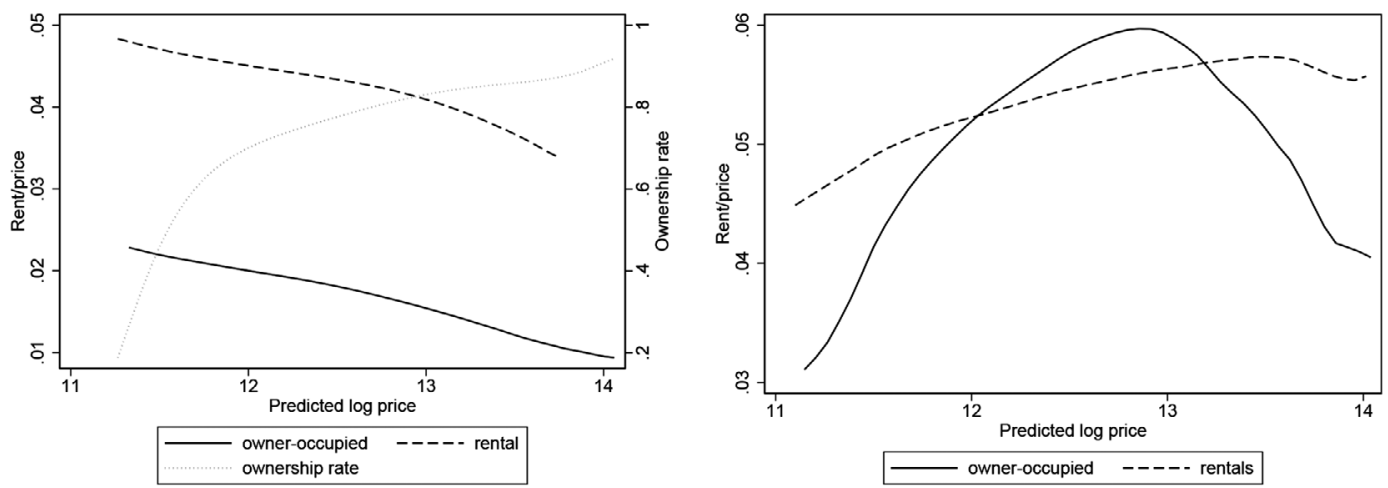

FIGURE 9

RENT-TO-PRICE RATIOS: BIASED (LEFT PANEL) AND UNBIASED (RIGHT PANEL)

less than one-for-one with property prices in the cross section. Halket and Pignatti Morano di Custoza (2015) show that some of this covariation can be explained by differences in rental vacancy rates.

The relationships shown in the left panel of Figure 9 and in these studies are puzzling and are a challenge for models that attempt to explain the distribution of household homeownership choices: Why do so many households choose to buy expensive properties when seemingly equivalent rental properties are relatively cheap? Estimates from our selection corrected model provide the answer. The rentals are not equivalent. More expensive rental sector prop- 
erties on average have lower unobserved quality. In the right panel of Figure 9, one can see that unbiased predictions of the rent-to-price ratio increase with predicted log price except for the most expensive owner-occupied properties.

\section{IMPLICATIONS FOR USER COST AND RENT-TO-PRICE RATIO}

6.1. User Costs and the Rent-to-Price Ratio. A hypothetical marginal investor's willingness to pay for a property in a sector, either $\pi_{o}(z, \varepsilon)$ or $\pi_{r}(z, \varepsilon)$, equals the property's stream of utility or rent flows, net of sector-specific maintenance, and discounted by the sector-specific opportunity cost or user cost of capital. A sector's user cost of capital is determined by the effective rate of interest, the cost of maintenance, and expectations about future capital gains, taking into account taxes, transactions costs, inflation, risk, and any option value from switching sectors. In Appendix A.5, we show that these relationships can be characterized by two Poterba-like user cost equations (Poterba, 1992):

$$
\begin{aligned}
\pi_{o}(z, \varepsilon) & =\frac{U(z, \varepsilon)}{r_{o}(z, \varepsilon)+c_{o}(z, \varepsilon)-g_{o}(z, \varepsilon)}, \\
\pi_{r}(z, \varepsilon) & =\frac{R(z, \varepsilon)}{r_{r}(z, \varepsilon)+c_{r}(z, \varepsilon)-g_{r}(z, \varepsilon)},
\end{aligned}
$$

where for each sector $i, r_{i}(z, \varepsilon)$ is the after-tax discount rate for the marginal investor in that property, $c_{i}(z, \varepsilon)$ is the cost of management and maintenance (including property taxes and amortized vacancy costs), and $g_{i}(z, \varepsilon)$ is the expected capital gain (including switching costs and any option value). $U(z, \varepsilon)$ is the utility flow for an owner-occupier.

Each element in these equations may vary both across property types and sector. Since tax policies and borrowing constraints frequently depend on tenure, there need not be a single discount rate that prices all property in equilibrium. ${ }^{14}$ Capital gains are not taxed for owneroccupiers but are taxed for landlords. We assume that this difference is subsumed in differences between $g_{o}$ and $g_{r}$. Lettings are exempt from value-added taxes in the United Kingdom, but net rental income may be subject to income taxes. Assuming a common income tax rate, this can be subsumed into $c_{r}(z, \varepsilon)$. Costs of vacancies in either sector can also be subsumed into $c_{i}$. Each element in the equations may vary across time as well. To keep notation simple, we do not denote any such time dependence in the equations.

In general, for a property of type $(z, \varepsilon)$, user costs in the two sectors will differ. Owners of properties will not in general be indifferent between the two sectors: Properties with relatively high rental sector user costs will be selected into the owner-occupied sector. Only for owners of properties at the margin, where $P(z, \varepsilon)=\pi_{o}(z, \varepsilon)=\pi_{r}(z, \varepsilon)$, do the two user cost equations (8)-(9) collapse to the more familiar, single-equation user cost formula (such as the one in Poterba, 1992). Elsewhere, for owners in the owner-occupied sector, $P(z, \varepsilon)=\pi_{o}(z, \varepsilon)>$ $\pi_{r}(z, \varepsilon)$, whereas for rental sector owners, $P(z, \varepsilon)=\pi_{r}(z, \varepsilon)>\pi_{o}(z, \varepsilon)$.

6.2. Identification of User Cost Distribution. We can use our results to obtain estimates of the user cost distribution. Let user costs be $u_{o}(z, \varepsilon)=\frac{U(z, \varepsilon)}{\pi_{o}(z, \varepsilon)}$ and $u_{r}(z, \varepsilon)=\frac{R(z, \varepsilon)}{\pi_{r}(z, \varepsilon)}$. The variable $u_{r}$ is also the yield on a rental property (gross of maintenance expenses). If we assume that the service flows from dwelling $(z, \varepsilon)$ are the same regardless of sector, then $R(z, \varepsilon)=$ $U(z, \varepsilon)$. Combining this with Equations (1)-(3) implies that

$$
\ln u_{o}=(\alpha-\beta) z+\varepsilon_{r}-\varepsilon_{o}
$$

\footnotetext{
${ }^{14}$ For example, mortgage interest payments are not deductible from taxable income in England for owneroccupiers but are for landlords. This may be reflected in differences between $r_{o}$ and $r_{r}$.
} 


$$
\ln u_{r}=\left(\alpha-\beta+\sqrt{\sigma_{s s}} \tilde{\gamma}\right) z+\varepsilon_{r}-\varepsilon_{o}+\sqrt{\sigma_{s s}} \widetilde{\varepsilon}_{s},
$$

where $\widetilde{\varepsilon}_{s}=\frac{\varepsilon_{s}}{\sqrt{\sigma_{s s}}}$. Equations (10) and (11) imply that the ratio of user costs satisfies:

$$
\ln u_{r}-\ln u_{o}=\sqrt{\sigma_{s s}} \tilde{\gamma} z+\sqrt{\sigma_{s s}} \widetilde{\varepsilon_{s}}
$$

User costs and yields depend on the estimated parameters $(\alpha, \beta, \tilde{\gamma})$ and on the unknown parameter $\sigma_{s s}$. In addition, the covariance matrix of the user costs depends on the unknown parameter $\rho_{\text {ro }}$.

As noted in Subsection 2.2, $\left(\sigma_{s s}, \rho_{r o}\right)$ are not point identified. We show in Appendix A.6 that $\rho_{r o}$ is partially identified and that $\rho_{r o} \in[0.407,0.867]$, To pin down $\sigma_{s s}$, additional information or assumptions are required. In Appendix A.6, we show how information on rental sector average yields from Bracke (2019) and assumptions about the relative variances of the unobservable components of rental and owner-occupied values can be used to calibrate a reasonable range of values for $\sigma_{s s}$. In the remainder of this section, we discuss qualitative and quantitative implications of our results for user costs and maintenance costs using two alternative calibrations, $\sigma_{s s}=\{0.16,0.6\}$. In each case, we fix $\rho_{r o}$ so that average rental sector yields are $6.2 \%$ as in Bracke (2019). The qualitative implications are robust to other reasonable choices for $\left(\sigma_{s s}, \rho_{r o}\right)$. We consider a range of values in Appendix A.6.

\subsection{Estimates.}

6.3.1. User cost variation with respect to location. As discussed above, the rent-to-price ratio increases with distance in several waves but decreases with distance in 2014. At the same time, location is unimportant for selection except possibly for distances very close to the center. Using Equation (12), these facts imply that differential users costs between the two sectors do not vary much with distance except for locations very close to the center. This can be seen in Figure 10 that shows average log user costs in each sector as a function of distance. The figure shows estimates for two distinct values of $\sigma_{s s}, \sigma_{s s}=0.16$ and $\sigma_{s s}=0.6$. At distances less than $10 \mathrm{~km}$, owner user costs increase with distance. The pattern is the same for both values of $\sigma_{s s}$. Rental sector user costs are higher than owner-sector user costs with a wedge that varies slightly with $\sigma_{s s}$; rental user costs are approximately $0.1 \log$ points higher when $\sigma_{s s}$ is large.

In other words, although the components of user costs (effective discount rates, maintenance costs, and expected capital gains) may vary with distance from London, they do not display significant differential variation across the two housing sectors. Considering the individual components of user costs, it is unlikely that the contributions of, for example, discount rates and maintenance costs vary differentially in such a way to cancel one another out. On the other hand, as discussed in Subsection 5.1, it is likely that both rental and owner-occupied maintenance costs as a proportion of value rise with distance.

6.3.2. Variation with respect to size and dwelling type. In Section 5, we found that the more detached and/or the larger a property is, the higher is its rent-to-price ratio but the lower is its likelihood of being a rental. Detachedness and size are each positively valued and are each negatively correlated with being in the rental sector. Rents rise faster than $\pi_{o}$ that, in turn, rises faster than $\pi_{r}$. So, gross yields for landlords, $R / \pi_{r}$, increase when the value of a property's physical structure increases. Considering Equations (8) and (9), this implies that either $r_{o} / r_{r}$ or $c_{o} / c_{r}$ decreases or $g_{o} / g_{r}$ increases with detachedness and with size. Additionally since $R / \pi_{r}$ increases, the user costs for landlords must be increasing.

Figures 11 and 12 show the resulting predictions for average log user costs as functions of size and dwelling type in the two sectors. Both figures show the same picture. User costs are 
1800

HALKET, NESHEIM, AND OSWALD

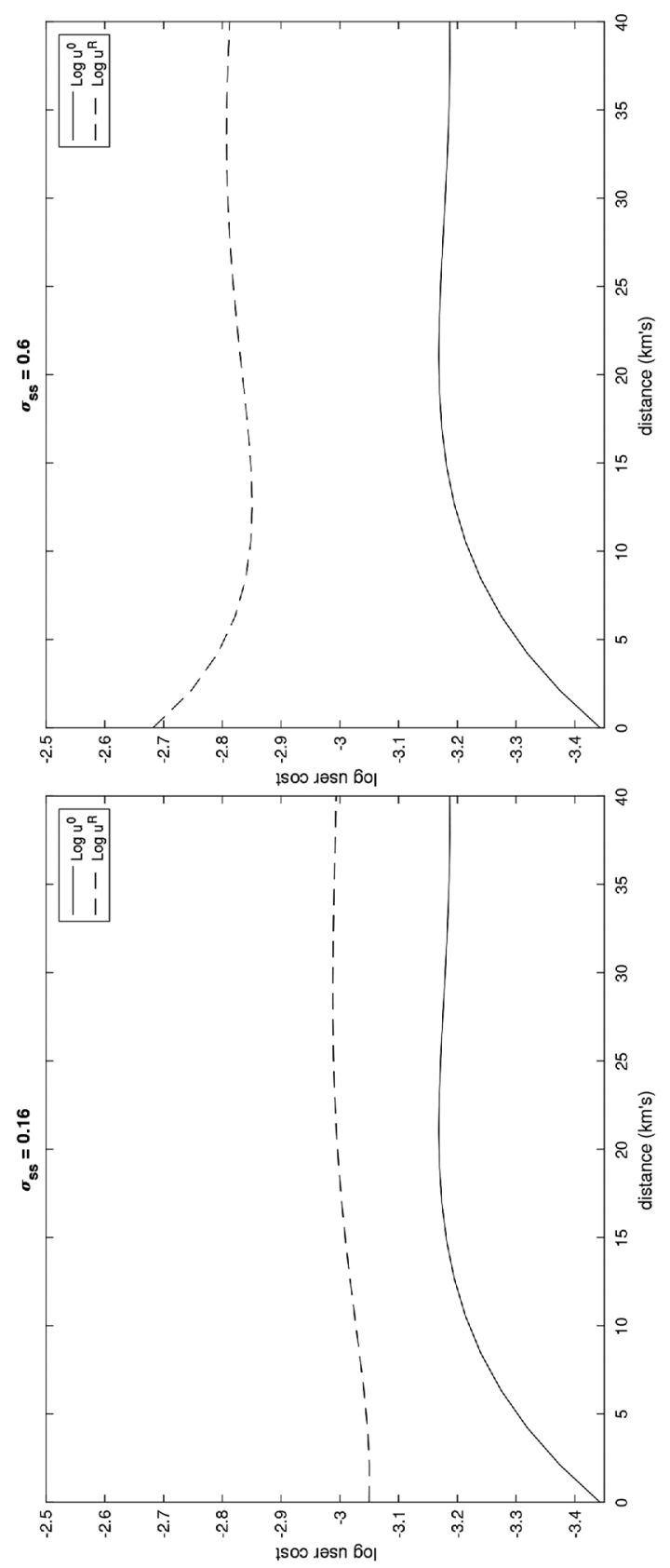

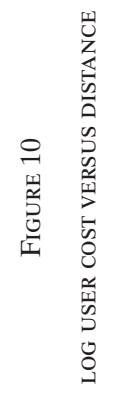




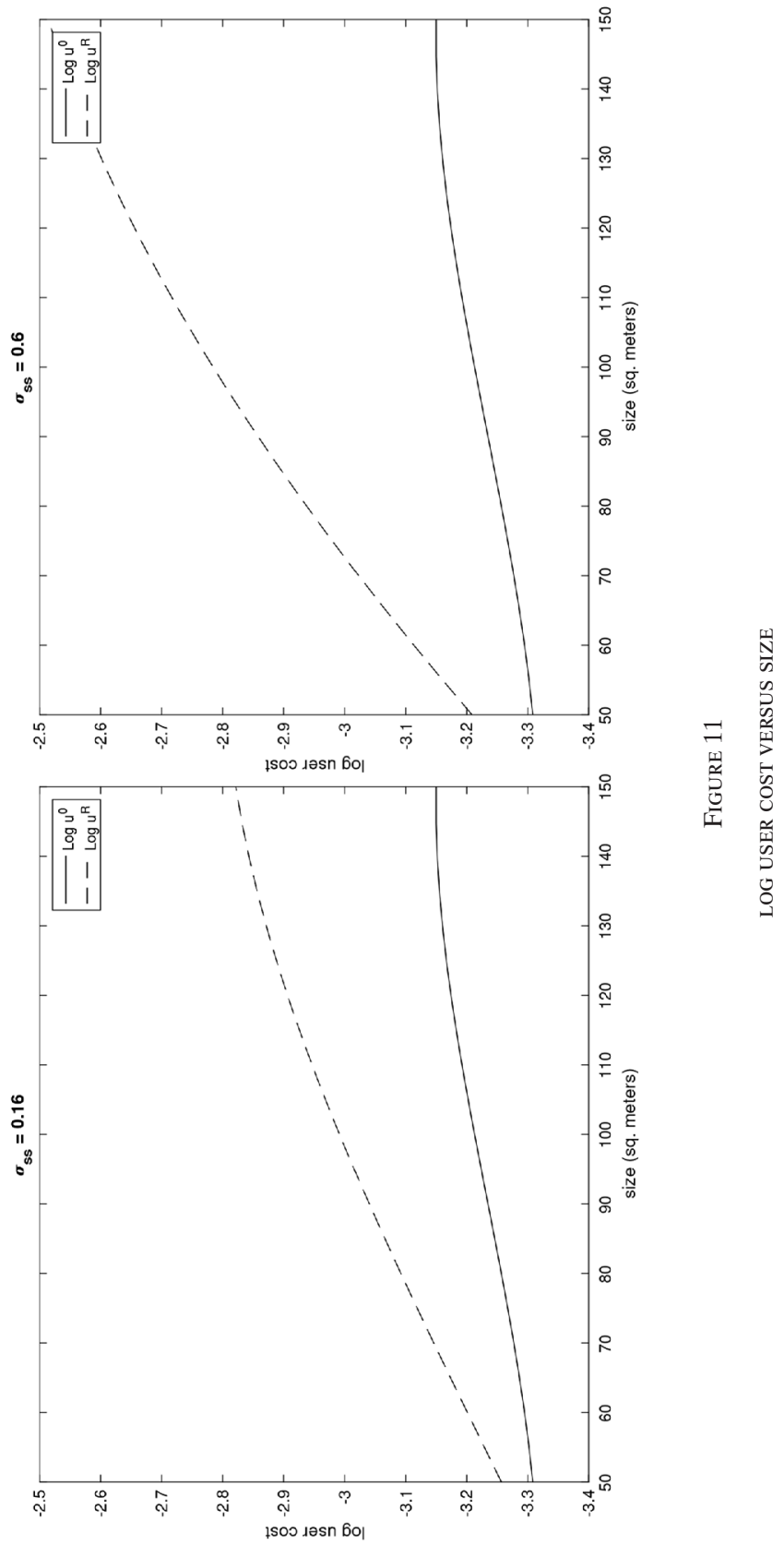




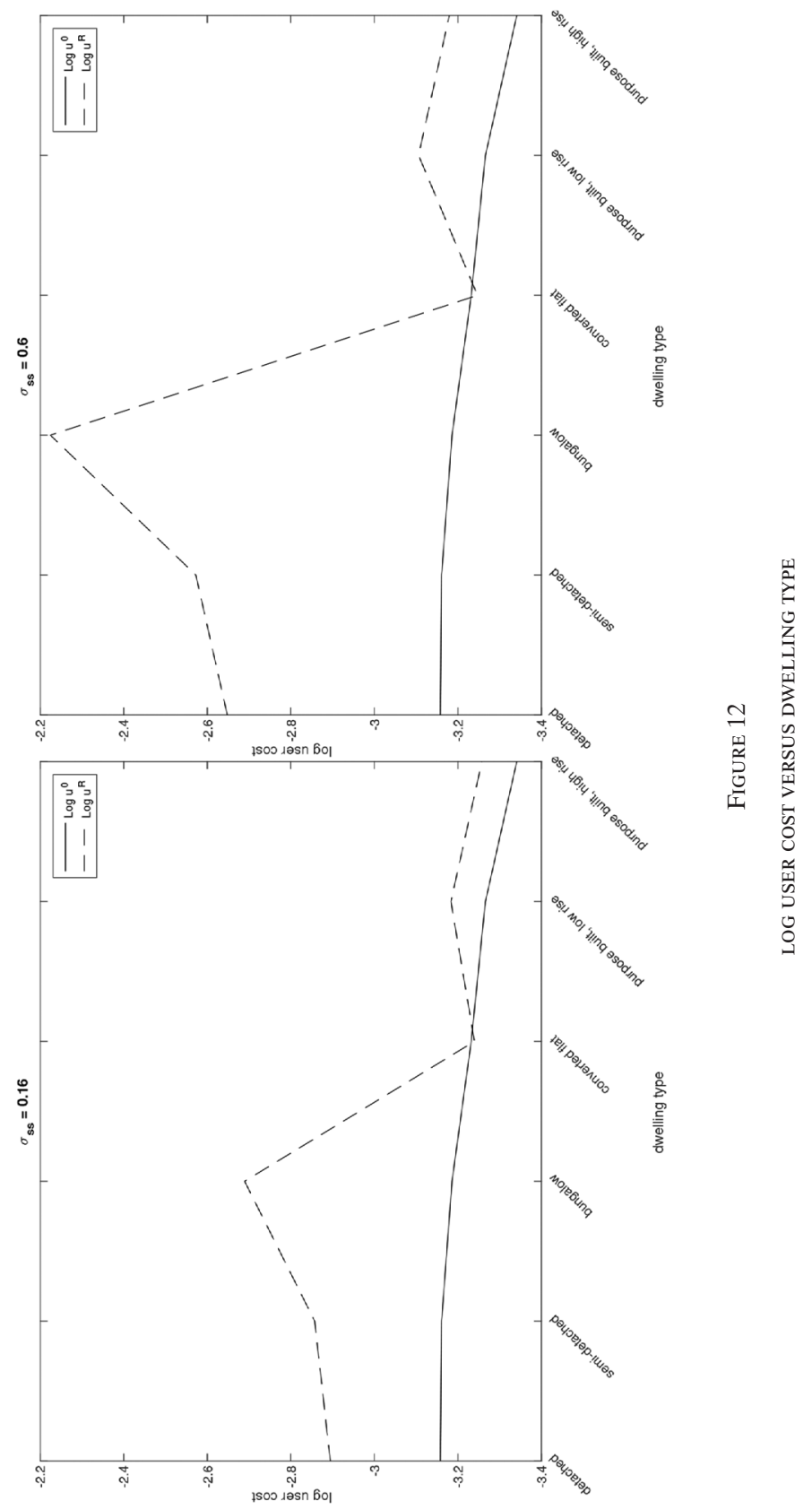


higher for bigger properties and for more detached properties. Rental sector user costs increase more with both size and for detached properties. The differential change is larger when $\sigma_{s s}$ is larger.

What explains these increases? It is unlikely that $g_{o} / g_{r}$ varies dramatically for units with different physical features (detached vs. multiunit or small vs. large flat). There may be small differences due to sectoral differences in taxation of capital gains. For instance, capital gains below a certain threshold are tax exempt for owner-occupiers. ${ }^{15}$ As discussed above, this suggests that even if expected capital gains vary with location, $g_{o} / g_{r}$ is roughly constant. Moreover, given that we find similar patterns with respect to physical features across all of our waves, any wedge in $g_{o} / g_{r}$ would have to persist in a way that could imply divergent prices (or a violation of rational expectations).

In contrast, in the case of costs, it is theoretically plausible that rental costs $c_{r}$ increase faster than $c_{o}$ when size increases or when one compares detached houses to dwellings in multiunit structures. This is the direct or indirect implication of the theories of Galster (1983), Henderson and Ioannides (1983), and Coulson and Fisher (2014). Our findings suggest that, if true, this differential increase in costs is large. We compute an estimate of an upper bound for this magnitude in Subsection 6.3.3.

In the case of interest costs, it is also theoretically plausible that interest costs for the marginal owner-occupier, $r_{o}$, decrease with size and detachedness. There is weak evidence in the EHS data that the loan-to-value ratio, and hence financing costs, at time of purchase falls with size for owner-occupiers in our sample. So, it is possible that contracting problems related to the physical structure lead to variation in and selection on both $c_{o} / c_{r}$ and $r_{o} / r_{r}$. Further investigation is required to determine whether and to what degree mortgage costs vary across owner-occupiers, across landlords, and across different types of housing units.

6.3.3. Implication for maintenance costs. Based on our above estimates, we can back out an estimate of how sector affects maintenance costs for a property if we make additional assumptions about the discount rates and expected capital gains. ${ }^{16}$ For instance, if we make the assumption that $r_{r}-g_{r}=r_{o}-g_{o}$, Equation (12) becomes:

$$
\frac{1+\frac{c_{r}}{r-g}}{1+\frac{c_{o}}{r-g}}=e^{\sqrt{\sigma_{s s}} \tilde{\gamma} z-\sqrt{\sigma_{s s}} \widetilde{\eta}_{s}} .
$$

In Figures 13-15, we calibrate $c_{o}=0.017$ (consistent with measures of owner-occupied depreciation in Malpezzi et al., 1987; Gatzlaff et al., 1998; Amior and Halket, 2014, among others) and set $r-g=0.01$ for both sectors. For each value of $\sigma_{s s} \in\{0.16,0.6\}$, we then plot the conditional and unconditional mean values of $c_{r}$ as functions of location, size, and dwelling type. The conditional mean functions show the means conditional on being either in the rental or the owner-occupied sector. The unconditional average, $E\left(c_{r}\right)$, which measures the average cost of maintenance if all properties were rented, is higher than $c_{o}$. In Figure 13, one can see that, regardless of $\sigma_{s s}$, it increases close to the center of London. It is about 1 percentage point higher at the center than distances greater than $5 \mathrm{~km}$. When $\sigma_{s s}=0.16$, it is nearly 1 percentage point higher than $c_{o}$. When $\sigma_{s s}=0.6$, it is 2 percentage points higher. The conditional mean, $E\left(c_{r} \mid\right.$ owner $)$, which measures the counterfactual cost of maintaining owner-occupied properties were they instead rented, is still higher; about 1 percentage point higher than the unconditional mean. In contrast, the conditional mean, E( $c_{r} \mid$ rent $)$ is lower. As one would

\footnotetext{
${ }^{15}$ Note also that any variation due to differential tax treatments should also be reflected in our findings with respect to location, which is not the case. Location is uncorrelated with ownership after controlling for observable and unobservable structural characteristics.

${ }^{16}$ One could do a similar exercise for, say, discount rates. We choose to focus on maintenance costs because such costs are part of national statistics and because our upper bound estimate may be helpful to researchers looking to calibrate a wedge in maintenance costs between the two sectors.
} 


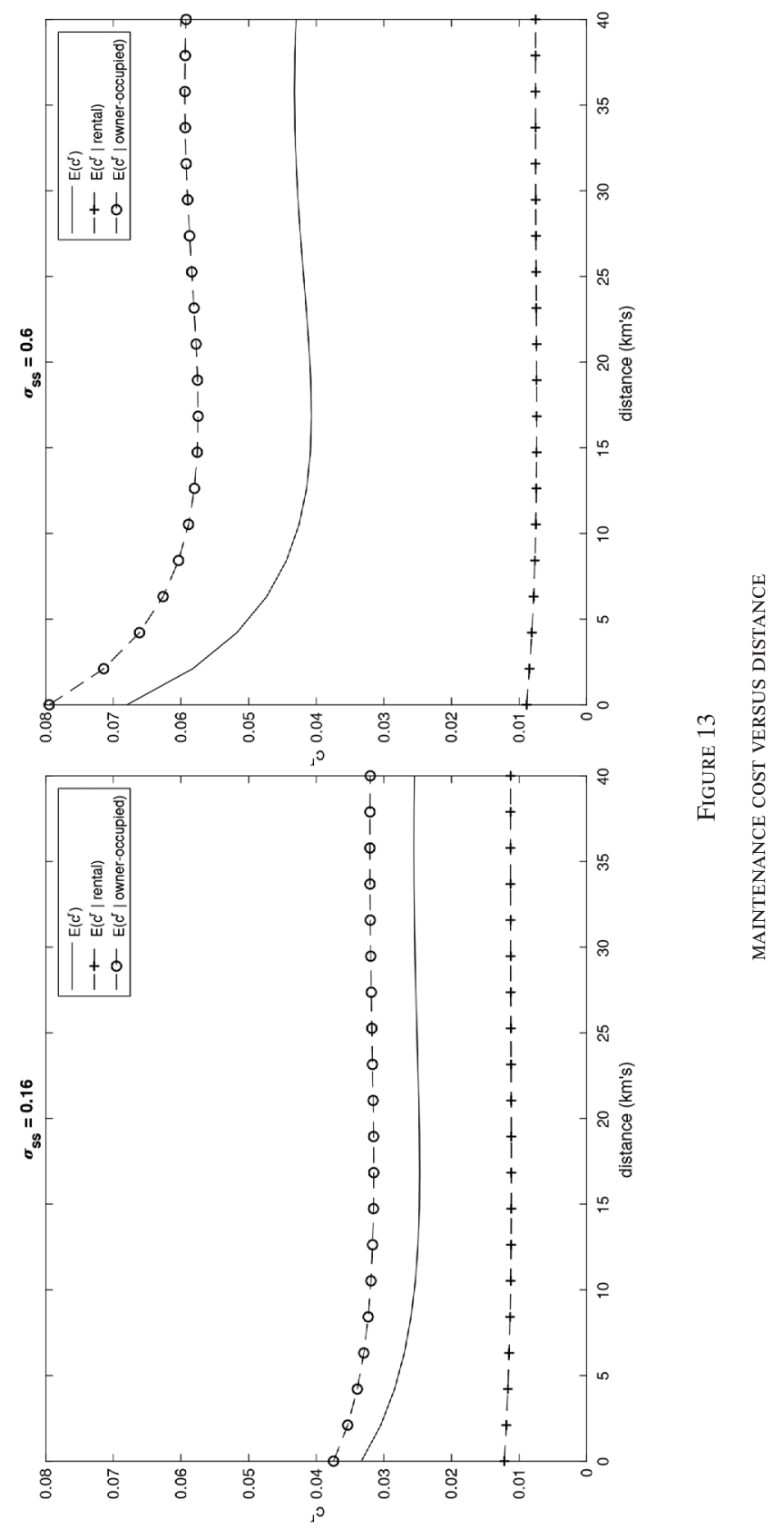




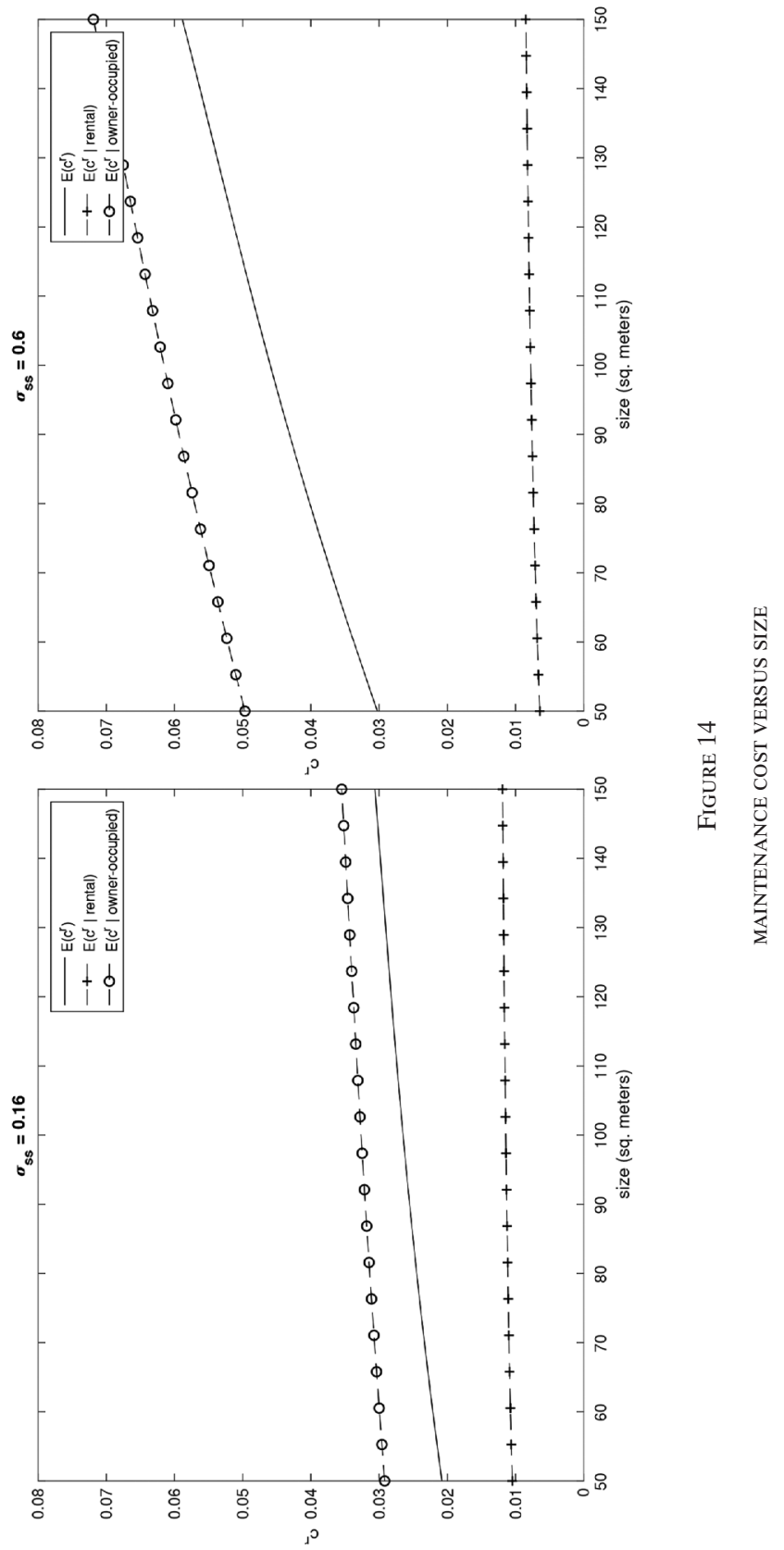




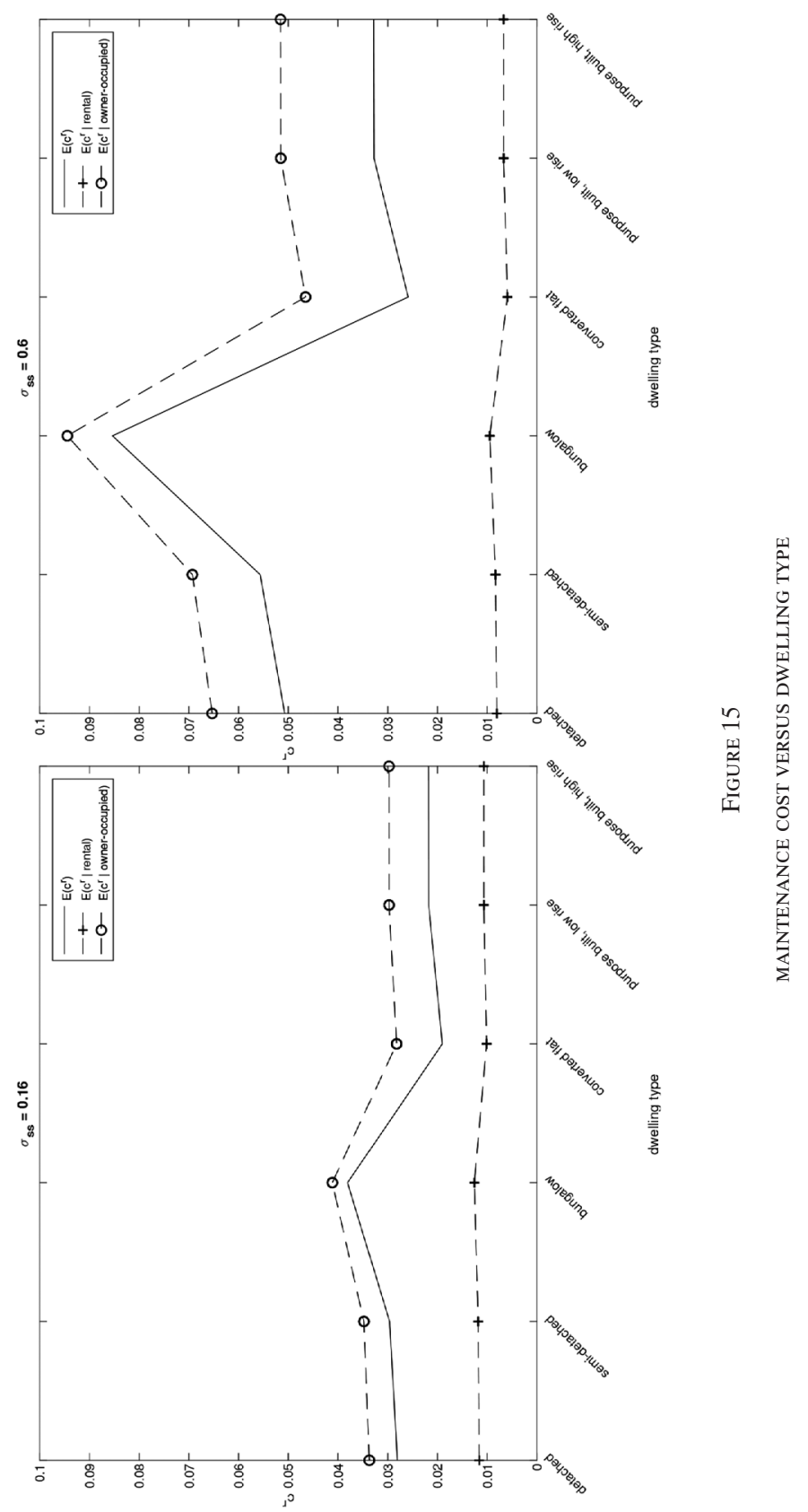


expect, properties in the rental sector have lower average renter-specific maintenance costs. This stems from the fact that these properties have lower unobserved rental quality.

Figure 14 shows analogous results for maintenance costs versus property size. In this case, the gap between $c_{r}$ and $c_{o}$ increases strongly with property size. $c_{r}$ increases by about 1 to 2 percentage points when property size increases from 50 to $150 \mathrm{~m}^{2}$, depending on $\sigma_{s s}$. The gap between the unconditional mean of $c_{r}$ and $E\left(c_{r} \mid\right.$ own $)$ is a little less than 1 percentage point when $\sigma_{s s}$ is low and nearly 2 percentage points when $\sigma_{s s}$ is high.

Finally, Figure 15 shows how maintenance costs vary with property type. The gap between $c_{r}$ and $c_{o}$ is larger for detached properties, 1-1.5 percentage points larger when $\sigma_{s s}=0.16$, and $3.5-6$ percentage points when $\sigma_{s s}=0.6$. And, like the previous findings, the gap between the conditional and unconditional mean is nearly twice as large when $\sigma_{s s}$ is larger.

These findings illustrate how maintenance costs vary with sector and with property characteristics. In all cases, the magnitudes are economically substantial. The findings also illustrate how the magnitudes vary with assumptions about $\sigma_{s s}$ and suggest why estimates of differential maintenance costs that do not control for selection fail to find higher costs in the rental sector. By assuming that all differences between the sectors are due to contracting frictions, they provide an upper bound on the moral hazard problem for landlords and tenants.

\section{CONCLUSION}

Housing units are not randomly selected into a housing sector. Physical attributes including some that are unobservable in our data are important for selection. Location is not. These findings are consistent with theories of contracting frictions over maintenance and upkeep of the property but may also perhaps be explained by other theories. Most existing models of households' homeownership decisions, such as Henderson and Ioannides (1983), Cocco (2005), Diaz and Luengo-Prado (2008), and Landvoigt et al. (2015), largely have abstracted away from explicit considerations of the multicharacteristic nature of housing units. To understand the puzzles of homeownership, our findings point to a need to examine both sectorspecific housing costs as well as, on the demand side, to model household choices of both ownership and housing characteristics. Perhaps, households who have a higher demand for larger housing units or detached houses or housing units with high maintenance amenities are more likely to save for a down payment everything else equal.

The results also imply that properly accounting for the bias that selection imparts may encourage refinements in the construction of price indices both for housing and for consumer prices as well as national accounts. It may also help to better understand some of the relative movements of rents and prices over time such as those documented in Campbell et al. (2009).

\section{APPENDIX}

A.1 Robustness of Empirical Results. In this appendix, we present results from several alternative specifications and also some measures of model fit. To test our baseline results for robustness, the alternative specifications add a large number of additional property characteristics to the baseline model and consider several candidate exclusion restrictions. Additional results are available in the Supplemental Appendix.

A.2 Alternate Specifications: Models 2-5. We considered several alternate specifications to gauge the robustness of our results to model specification. We label these alternate specification Model 2-5. Each of these specifications adds a set of additional property and locational characteristics to our baseline model to see whether additional variables change our results. We report a subset of results from these in Table 6. Further results for all models are reported in the Supplementary Appendix.

Model 2 adds bedrooms, bathrooms, living rooms, number of big kitchens, and fireplaces and indicators for attics, balconies, and basements to Model 1. Model 3 adds to Model 2 mea- 
sures of housing quality defined as the first five principal components of a set of more than 60 measures of property quality. Model 4 adds to Model 3 the first three principal components from a set of more than 40 measures of neighborhood quality. Finally, Model 5 adds the first four principal components from a set of six additional neighborhood variables.

The additional variables included in Models 3-5 are defined as follows: The EHS contains more than 60 measures of property quality including: measures of whether the property meets "decent homes criteria" (these are criteria set by the government to measure thermal comfort, "reasonable" state of repair, etc.), the estimated cost to upgrade to meet those criteria, several measures of accessibility (for wheelchair users or disabled), indicators of various problems (e.g., rising damp, inadequate lighting or ventilation, etc.), several measures of interior stair features, several measures of dwelling security, and several measures of health and safety problems. All variables are assessed by a professional surveyor. We conducted a principal component analysis of these quality measures and based on a scree test selected the first five principal components to include in the model. These five principal components account for $49.8 \%$ of the variation in these quality variables. These variables are included in Models 3-5.

Similarly, the EHS contains more than 40 measures of neighborhood quality, including measures of neighborhood noise (e.g., neighbors, traffic noise, trains, planes, etc.), neighborhood problems (e.g., litter, graffiti, vandalism, air quality, etc.), and neighborhood quality (e.g., visual quality as rated by surveyor, whether resident feels safe, etc.). As above, all variables are assessed by a professional surveyor. We conducted a principal components analysis of these neighborhood variables and based on a scree test selected the first three principal components to include in the model. The first three principal components accounted for $61.5 \%$ of the variance of the neighborhood variables. These variables are included in Models 4-5.

Finally, Model 5 included an additional set of neighborhood variables derived from six additional measures of the local neighborhood including urban nature, and the density, type, and age of neighboring structures. We conducted a principal components analysis of these variables. Based on a scree test, we selected the first four principal components that account for $57 \%$ of the variation of these variables.

Most of the estimates of common parameters are statistically indistinguishable across the specifications in Models 2-5. In particular, as seen in Table 6, our estimates of $\rho_{r s}$ and $\rho_{o s}$ are statistically indistinguishable across specifications. For that reason, we do not discuss Models 3-5 further here.

However, because the numbers of various rooms are highly correlated with size and dwelling type, the Model 2 results do have some notable differences from Model 1 in these dimensions. For this reason, we discuss these results more in Subsection 5.2.2 and show that the important qualitative results are similar across the two models. Despite the differences, we prefer the more parsimonious Model 1 because the Model 2 results are less precise due to the high correlation between numbers of rooms and size.

A.3 Exclusion Restrictions. Models 1-5 do not employ any exclusion restrictions. The EHS contains information on a large range of property characteristics and neighborhood characteristics. After searching through the variables in the survey, we concluded that all of the variables detailed above provide measures of housing characteristics that potentially affect prices, rents, and allocation to sectors. Therefore, in our view, none could be excluded from the pricing equations a priori. So, we sought for additional variables that could be plausibly excluded from either the rent or the value equation. However, any variable that affects the present value of a property will likely also affect both the owner-occupied value $\pi_{o}$ and the rent $R$. If one observed some measure of switching costs that is uncorrelated with $\varepsilon_{r}$ and $\varepsilon_{o}$, one could use such a measure as an instrument for selection. Lagged sector choices do not qualify because they are correlated with $\varepsilon_{r}$ and $\varepsilon_{o}$.

One possibility would be historical events or political or legal restrictions that affected a property's sectoral allocation but not its value. Variables proxying for such events or 
restrictions could be included in the selection equation and legitimately could be excluded from the pricing equations. For example, the U.K. government introduced a "Build to Rent" scheme in September 2012 that subsidized construction of affordable rental properties under some restrictions. We investigated using local measures of the effects of this scheme as variables to shift sectoral allocations. However, there were two problems. First, none of the subsidized properties were completed until 2015, outside the period covered by our sample. Second, although the details of the scheme varied by locality, many, if not all, schemes included restrictions that would likely affect both rents and values hence violating the exclusion conditions.

Despite these considerations, geographic indicators might serve as useful proxies for local government policies that affect sector allocations. To test this, we considered four additional specifications that use geographic indicators as proxies for unobserved local policies. We label these models as Model 6-Model 9. Model 6 includes county fixed effects in the selection equation. It would have been better to use LA or postcode district fixed effects, but this was not possible given our sample size. If local policies on sector choice vary across counties but market conditions do not (conditional on distance, direction, and location quality), then it would be valid to exclude county fixed effects from the pricing equations. Model 7 includes a variable that measures the fraction of dwellings in the LA area that are "right-to-buy" dwellings. Right-to-buy dwellings are dwellings that were formerly social housing but that have been sold. The fractions that are right-to-buy may reflect historical local political decisions that are independent from a dwelling's characteristics. Model 8 includes the predicted share of social housing in the LA. This may be a valid instrument for reasons similar to those above. Finally, Model 9 includes a measure of the predominant "tenure" of properties in the LA area (i.e., privately built, LA built, etc.). As above, this variable may be correlated with historical local policies that are independent of dwelling characteristics.

Results from Models 6-9 are detailed in the Supplementary Appendix. For Model 6, the county fixed effects are jointly significant but do not change any of our results. For Models 79 , the additional variables have no first stage predictive power and so change nothing. We also tried combinations of these variables. Results were unchanged in all specifications.

A.4 Model Fit. The model fits prices in the owner-occupied sector better than it fits rents in the rental sector. In the owner-occupied sector, the $R^{2}$ is 0.686 ; the model explains $68.6 \%$ of the variance of $\log$ prices. In the rental sector, the model explains only $43.3 \%$. A larger share of the variance in rents is due to unobserved characteristics. This could be due to more unobservable physical characteristics of the property being priced into rents than prices, perhaps due to higher expected depreciation of many unobserved components or to the shorter expected duration of renters (i.e., renters care about the color of the paint on the walls because they are not willing or perhaps contractually able to repaint the walls; owners are more willing to repaint). It may also be because rents further vary with various tenant and landlord characteristics, such as the age of the tenant or whether the landlord is a professional or corporate landlord. Adding characteristics of the tenant and landlord into our model would add further selection issues that are beyond the scope of this article (see, e.g., Ackerberg and Botticini, 2002).

We can also look at how well the selection model performs in terms of classifying properties as rental or owner-occupied properties. Table A1 shows percentiles of the predicted ownership probabilities by sector. For owner-occupied properties, all models perform equally well. Ninety percent of owner-occupied properties have predicted ownership probabilities higher than 0.63 . For rental properties, the classification probabilities are less strongly separated. Fifty percent of rental properties have predicted ownership probabilities higher than $62 \%-$ $66 \%$. This is not surprising since $81 \%$ of properties are owner-occupied. For rental sector properties, the five models agree for all but the 1 st percentile of rental properties. 
TABLE A1

DISTRIBUTION OF PREDICTED PROBABILITY OF BEING OWNER-OCCUPIED

\begin{tabular}{|c|c|c|c|c|c|}
\hline & Model 1 & Model 2 & Model 3 & Model 4 & Model 5 \\
\hline \multicolumn{6}{|c|}{ Rental properties } \\
\hline $\mathrm{p} 1$ & 0.201 & 0.127 & 0.111 & 0.096 & 0.091 \\
\hline p10 & 0.354 & 0.298 & 0.3 & 0.294 & 0.294 \\
\hline $\mathrm{p} 25$ & 0.463 & 0.451 & 0.453 & 0.455 & 0.443 \\
\hline p50 & 0.655 & 0.638 & 0.63 & 0.619 & 0.619 \\
\hline p75 & 0.813 & 0.804 & 0.802 & 0.802 & 0.803 \\
\hline p90 & 0.905 & 0.906 & 0.903 & 0.906 & 0.904 \\
\hline p99 & 0.979 & 0.973 & 0.979 & 0.979 & 0.976 \\
\hline \multicolumn{6}{|c|}{ Owner-occupied properties } \\
\hline $\mathrm{p} 1$ & 0.333 & 0.339 & 0.356 & 0.343 & 0.34 \\
\hline p10 & 0.627 & 0.631 & 0.628 & 0.628 & 0.631 \\
\hline $\mathrm{p} 25$ & 0.794 & 0.792 & 0.793 & 0.795 & 0.794 \\
\hline p50 & 0.893 & 0.901 & 0.903 & 0.903 & 0.901 \\
\hline p75 & 0.949 & 0.957 & 0.957 & 0.957 & 0.958 \\
\hline p90 & 0.976 & 0.98 & 0.981 & 0.981 & 0.983 \\
\hline p99 & 0.996 & 0.996 & 0.996 & 0.996 & 0.998 \\
\hline
\end{tabular}

Notes: For each sector and model, the table shows percentiles of the distribution of predicted ownership probabilities.

A.5 User Costs in a Two-Sector Model with Switching. Time is discrete. Define the flow value (in nondurable consumption units) from occupying a property of type $(z, \varepsilon)$ in sector $i$ as $U_{i}(z, \varepsilon)$. Assume that sector-specific maintenance costs (including property taxes) are $c_{i}(z, \varepsilon) \pi_{i}(z, \varepsilon)$ and opportunity cost of capital is $r_{i}(z, \varepsilon)$. To simplify notation below, assume that maintenance costs are paid at the end of each time period. Let $g_{i}^{*}(z, \varepsilon)$ be the stochastic sector-specific after-tax capital gains and costs of switching to sector $j$ are $s_{j}(z, \varepsilon) \pi_{j}(z, \varepsilon)$. Then, the present value of a property in a sector $i$ is

$$
\begin{gathered}
\pi_{i}(z, \varepsilon) \\
=U_{i}(z, \varepsilon)-\frac{c_{i}(z, \varepsilon) \pi_{i}(z, \varepsilon)}{1+r_{i}(z, \varepsilon)} \\
+\frac{E\left(\max _{i, j}\left\{\left[1+g_{i}^{*}(z, \varepsilon)\right] \pi_{i}(z, \varepsilon),\left[1+g_{j}^{*}(z, \varepsilon)-s(z, \varepsilon)\right] \pi_{j}(z, \varepsilon)\right\}\right)}{1+r_{i}(z, \varepsilon)} .
\end{gathered}
$$

Thus, property value equals the current net utility flow plus the discounted expected future value. The future value includes an option value from the option to switch sectors.

Define the sector-specific expected capital gains function $g_{i}(z, \varepsilon)$ as

$$
1+g_{i}(z, \varepsilon)=E\left(\max _{i, j}\left\{1+g_{i}^{*}(z, \varepsilon),\left[1+g_{j}^{*}\left(z^{\prime}, \varepsilon^{\prime}\right)-s_{j}(z, \varepsilon)\right] \frac{\pi_{i}(z, \varepsilon)}{\pi_{j}(z, \varepsilon)}\right\}\right) .
$$

Note that $g_{i}(z, \varepsilon)$ includes both expected capital gains and the option value of switching sectors net of switching costs. Using this definition, equation (A.1) can be rewritten as

$$
\begin{aligned}
& U_{i}(z, \varepsilon)=\left[\frac{c_{i}(z, \varepsilon)+r_{i}(z, \varepsilon)-g_{i}(z, \varepsilon)}{1+r_{i}(z, \varepsilon)}\right] \pi_{i}(z, \varepsilon) \\
& \approx\left[c_{i}(z, \varepsilon)+r_{i}(z, \varepsilon)-g_{i}(z, \varepsilon)\right] \pi_{i}(z, \varepsilon) .
\end{aligned}
$$

The approximation becomes exact as the duration of the time period shrinks.

Finally, for a competitive landlord, rents equal the flow value of occupancy, so $R(z, \varepsilon)=$ $U_{r}(z, \varepsilon)$. Equations (8) and (9) follow. 


\section{A.6 Set Identification of $\rho_{\text {ro }}$ and $\sigma_{s s}$. Let}

$$
C=\left[\begin{array}{ccc}
1 & \rho_{r o} & \rho_{r s} \\
\rho_{r o} & 1 & \rho_{o s} \\
\rho_{r s} & \rho_{o s} & 1
\end{array}\right]
$$

be the correlation matrix corresponding to the covariance matrix $\Sigma$. From the discussion in Subsection 2.2, two of the three correlations in the matrix are identified. We have $\rho_{r s}=\frac{\widetilde{\sigma}_{r s}}{\sqrt{\sigma_{r r}}}$ and $\rho_{o s}=\frac{\widetilde{\sigma}_{o s}}{\sqrt{\sigma_{o o}}}$. The remaining correlation parameter, $\rho_{r o}$, is not point identified. However, it is partially identified because $C$ must be a valid correlation matrix: the absolute values of the individual correlations must be less than or equal to 1 and the determinant of $C$ must be nonnegative. This latter condition is

$$
\begin{aligned}
1+2 \rho_{r o} \rho_{r s} \rho_{o s}-\rho_{r o}^{2}-\rho_{r s}^{2}-\rho_{o s}^{2} & \geq 0 \\
1-\rho_{r s}^{2}-\rho_{o s}^{2}+\rho_{r s}^{2} \rho_{o s}^{2} & \geq\left(\rho_{r o}-\rho_{r s} \rho_{o s}\right)^{2} \\
\left(1-\rho_{r s}^{2}\right)\left(1-\rho_{o s}^{2}\right) & \geq\left(\rho_{r o}-\rho_{r s} \rho_{o s}\right)^{2},
\end{aligned}
$$

which implies that

$\rho_{r s} \rho_{o s}-\sqrt{1-\rho_{r s}^{2}} \sqrt{1-\rho_{o s}^{2}} \leq \rho_{r o} \leq \rho_{r s} \rho_{o s}+\sqrt{1-\rho_{r s}^{2}} \sqrt{1-\rho_{o s}^{2}}$.

Combining these inequalities with the point estimates in Table $5, \rho_{r s}=0.951$ and $\rho_{o s}=0.667$, we obtain $\rho_{r o} \in[0.407,0.867]$. Thus, we find that unobserved rental and owner quality are positively correlated and that the correlation is relatively strong, being at least 0.407 .

The identified set for $\sigma_{s s}$ cannot be pinned down in the same way. Additional information or additional assumptions are required. To point identify (or calibrate) both $\sigma_{s s}$ and $\rho_{r o}$, one would need to use two moments outside of our model. We show how information on rental sector average yields from Bracke (2019) and assumptions about the relative variances of the unobservable components of rental and owner-occupied values can be used to calibrate a reasonable range of values for $\sigma_{s s}$ and to further narrow the range of feasible values for $\rho_{r o}$. For example, given that $\rho_{r o} \in[0.407,0.867]$ as above, to match Bracke's estimated average rental sector yield of $6.2 \%$ requires that $\sigma_{s s} \in[0.0001,0.6]$. Varying $\sigma_{s s}$ within this interval then pins down the relative variances of the unobservable components and $\rho_{r o}$. For example, $\sigma_{s s}=0.16$ implies that the relative variances of the unobservable components of rental and owner-occupied properties' values are equal and that rental sector yields are relatively high compared to yields of observably equivalent owner-occupied properties, whereas $\sigma_{s s}=0.60$ implies that the former is 4.2 times greater and that rental sector yields are relatively low. Although we cannot rule out that $\sigma_{s s}$ takes on values smaller than 0.16 , extremely small values are implausible since they imply unobservables play no role in selection (this is not mathematically impossible but seems unlikely given our probit model does not perfectly predict sector), high rental yields, and that $\rho_{\text {ro }}$ must be near the top of the identified set.

In particular, the variance of the unobservable component of log rental sector value is

$\operatorname{Var}\left(\varepsilon_{o}-\varepsilon_{s}\right)=\sigma_{o o}+\sigma_{s s}-2 \sigma_{o s}$

A value for $\sigma_{s s}$ can be obtained from knowledge of the ratio $\operatorname{Var}\left(\varepsilon_{o}-\varepsilon_{s}\right) / \operatorname{Var}\left(\varepsilon_{o}\right)$. The ratio measures the importance of unobservables in explaining the variance in landlords' valuations relative to owner-occupiers'. For example, $\sigma_{s s}=0.160$ implies that the ratio equals 1 . The value $\sigma_{s s}=0.315$ implies a ratio of $2, \sigma_{s s}=0.447$ implies a ratio of 3 , and $\sigma_{s s}=0.6$ implies a ratio of 4.2. 
Since $\varepsilon$ is normally distributed, our model implies that the conditional mean rental sector yield is

$$
\begin{aligned}
\left.E\left(u_{r} \mid \text { rental }\right)\right) & \left.\left.=\int_{z} E\left(u_{r} \mid z, \tilde{\varepsilon}_{s} \leq-\tilde{\gamma} z\right)\right) f(z \mid \text { rental })\right) d z \\
& \left.=\int_{z} \frac{\Phi\left(-\tilde{\gamma} z-\Psi_{12}\right)}{\Phi(-\tilde{\gamma} z)} e^{\left(\alpha-\beta+\sqrt{\sigma_{s s}} \tilde{\gamma}\right) z+0.5 \Psi_{11}} f(z \mid \text { rental })\right) d z
\end{aligned}
$$

where $\Psi_{12}=\operatorname{Cov}\left(\widetilde{\varepsilon}_{s}, \varepsilon_{r}-\varepsilon_{o}+\sqrt{\sigma_{s s}} \widetilde{\varepsilon}_{s}\right)$ and $\Psi_{11}=\operatorname{Var}\left(\varepsilon_{r}-\varepsilon_{o}+\sqrt{\sigma_{s s}} \widetilde{\varepsilon}_{s}\right)$. Expected yield depends on our parameter estimates $\tilde{\gamma}$, our data $f(z \mid$ rental $)$, and the two parameters $\left(\rho_{\text {ro }}, \sigma_{s s}\right)$. Expected yields are decreasing in both $\rho_{\text {ro }}$ and $\sigma_{s s}$.

Figure 3 in Bracke (2019), based on data on rents and prices for the U.K. buy-to-let market, shows that the average rental sector yield in London in 2009-2014 was 0.062. Combining this estimate with Equation (A.2), using the range of values $\rho_{r o} \in[0.407,0.867]$, we find $\sigma_{s s} \in[0.0001,0.6]$. If Bracke's number is an underestimate of rental sector yields, then the upper bound on $\sigma_{s s}$ is lower. If Bracke's number is an overestimate, then $\sigma_{s s}$ could be higher. However, as discussed above, larger values imply large values for the variance of the unobserved component of log rental values. Although we cannot rule out that $\sigma_{s s}$ takes on values smaller than 0.16 , extremely small values are implausible since they imply that unobservables play no role in selection (this is not mathematically impossible but seems unlikely given our probit model does not perfectly predict sector), high rental yields, and that $\rho_{r o}$ must be near the top of the identified set. For these reasons, we consider nonnegligible values of $\sigma_{s s}$ to be the most plausible.

One can see how various values of $\left(\sigma_{s s}, \rho_{r o}\right)$ affect predicted yields in the following table:

DISTRIBUTION OF PREDICTED PROBABILITY OF BEING OWNER-OCCUPIED

\begin{tabular}{lllll}
\hline & & & $\rho_{\text {ro }}$ & \\
$\sigma_{s s}$ & 0.407 & 0.614 & 0.729 & 0.867 \\
\hline 0.16 & 0.074 & 0.062 & 0.056 & 0.05 \\
0.315 & 0.069 & 0.058 & 0.052 & 0.046 \\
0.447 & 0.065 & 0.055 & 0.050 & 0.043 \\
0.6 & 0.062 & 0.054 & 0.048 & 0.042 \\
\hline
\end{tabular}

Yields are decreasing in both $\rho_{r o}$ and $\sigma_{s s}$.

\section{SUPPORTING INFORMATION}

Additional supporting information may be found online in the Supporting Information section at the end of the article.

Data S1: bbl

Data S2: Appendix

Table A.1: Summary statistics by sector

Table A.2: $\log$-value equation (1.2): Models 1-5

Table A.3: Log-rent equation (1.1): Models 1-5

Table A.4: Selection equation (1.3): Models 1-5

Table A.5: Log-value equation (1.2): Models 6-9

Table A.6: Log-rent equation (1.1): Models 6-9

Table A.7: Selection equation (1.3): Models 6-9

Supplementary Appendix 


\section{REFERENCES}

Ackerberg, D. A., AND M. Botticini, "Endogenous Matching and the Empirical Determinants of Contract Form," Journal of Political Economy 110 (June 2002), 564-91.

Amemiya, T., Advanced Econometrics (Cambridge, MA: Harvard University Press, 1985).

Amior, M., and J. Halket, "Do Households Use Homeownership to Insure Themselves? Evidence across U.S. Cities," Quantitative Economics 5 (November 2014), 631-74.

Bracke, P., "House Prices and Rents: Microevidence from a Matched Data Set in Central London," Real Estate Economics 43 (2015), 403-31.

_ "How Much Do Investors Pay for Houses?" Real Estate Economics (March 2019), 1-33.

Campbell, J. Y., And J. F. Cocco, "How Do House Prices Affect Consumption? Evidence from Micro Data," Journal of Monetary Economics 54 (April 2007), 591-621.

Campbell, S. D., M. A. Davis, J. Gallin, and R. F. Martin, "What Moves Housing Markets: A Variance Decomposition of the Rent-Price Ratio," Journal of Urban Economics 66 (September 2009), 90-102.

Casas-Arce, P., and A. Saiz, "Owning versus Renting: Do Courts Matter?," Journal of Law and Economics 53 (2010), 137-65.

Chambers, M., C. Garriga, and D. Schlagenhauf, "The Loan Structure and Housing Tenure Decisions in an Equilibrium Model of Mortgage Choice," Review of Economic Dynamics 12 (July 2009a), $444-68$.

_Accounting for Changes in the Homeownership Rate," International Economic Review 50 (2009b), 677-726.

Chen, K., "A Life-Cycle Analysis of Social Security with Housing," Review of Economic Dynamics 13 (July 2010), 597-615.

Cocco, J., "Portfolio Choice in the Presence of Housing," Review of Financial Studies 18 (2005), 535-67.

Coulson, N. E., AND L. M. Fisher, "Houses, Apartments and Condos: The Governance of Multifamily Housing," Technical Report, Penn State University, January 2014.

Department for Communities and Local Government, "English Housing Survey, 2008-2014: Secure Access. 6th Edition," Technical Report SN: 6923, UK Data Service, http://doi.org/10.5255/UKDA-SN6923-6, 2017.

Diaz, A., and M. J. Luengo-Prado, "On the User Cost and Homeownership," Review of Economic Dynamics 11 (2008), 584-613.

Epple, D., L. Quintero, And H. Sieg, “A New Approach to Estimating Hedonic Equilibrium Models for Metropolitan Housing Markets," Journal of Political Economy 128 (2020), 948-83.

Galster, G. C., "Empirical Evidence on Cross-Tenure Differences in Home Maintenance and Conditions," Land Economics 59 (1983), 107-13.

Garner, T. I., ANd R. Verbrugge, "The Puzzling Divergence of US Rents and User Costs, 1980-2004: Summary and Extensions," Price and Productivity Measurement 1 (2009), 125-46.

Gatzlaff, D. H., R. K. Green, and D. C. Ling, "Cross-Tenure Differences in Home Maintenance and Appreciation," Land Economics 74 (1998), 328-42.

Giglio, S., M. Maggioni, and J. Stroebel, "Very Long-Run Discount Rates," The Quarterly Journal of Economics 130 (2015), 1-53.

Glaeser, E. L., AND J. M. Shapiro, "The Benefits of the Home Mortgage Interest Deduction," in Tax Policy and the Economy, Volume 17 of NBER Chapters (Cambridge, MA: National Bureau of Economic Research, 2003), 37-82.

Goodman, A. C., "An Econometric Model of Housing Price, Permanent Income, Tenure Choice, and Housing Demand," Journal of Urban Economics 23 (1988), 327-53.

Halket, J., and M. Pignatti Morano di Custoza, "Homeownership and the Scarcity of Rentals," Journal of Monetary Economics 76 (2015), 107-23.

Hanson, A., "Size of Home, Homeownership, and the Mortgage Interest Deduction," Journal of Housing Economics 21 (2012), 195-210.

Harding, J., T. J. Miceli, And C. Sirmans, "Do Owners Take Better Care of Their Housing Than Renters?," Real Estate Economics 28 (2000), 663-81.

Henderson, J. V., and Y. M. Ioannides, “A Model of Housing Tenure Choice,” American Economic Review 73 (1983), 98-113.

Heston, A., And A. O. Nakamura, "Questions about the Equivalence of Market Rents and User Costs for Owner Occupied Housing," Journal of Housing Economics 18 (2009), 273-9.

Hilber, C. A., "Neighborhood Externality Risk and the Homeownership Status of Properties," Journal of Urban Economics 57 (March 2005), 213-41.

Iacoviello, M., AND M. Pavan, "Housing and Debt over the Life Cycle and over the Business Cycle," Journal of Monetary Economics 60 (2013), 221-38.

KAN, K., "Dynamic Modeling of Housing Tenure Choice," Journal of Urban Economics 48 (2000), 4669. 
Kiyotaki, N., A. Michaelides, And K. Nikolov, "Winners and Losers in Housing Markets," Journal of Money, Credit and Banking 43 (2011), 255-96.

Landvoigt, T., M. Piazzesi, And M. Schneider, "The Housing Market(s) of San Diego," American Economic Review 105 (2015), 1371-407.

LeE, L.-F., AND R. P. Trost, "Estimation of Some Limited Dependent Variable Models with Application to Housing Demand," Journal of Econometrics 8 (1978), 357-82.

Linneman, P., "An Economic Analysis of the Homeownership Decision," Journal of Urban Economics 17 (1985), 230-46.

Malpezzi, S., L. Ozanne, and T. G. Thibodeau, "Microeconomic Estimates of Housing Depreciation," Land Economics 63 (1987), 372-85.

Oswald, F., "The Effect of Homeownership on the Option Value of Regional Migration," Quantitative Economics 10 (2019), 1453-93.

Poterba, J. M., "Taxation and Housing: Old Questions, New Answers," American Economic Review 82 (May 1992), 237-42.

Prabhala, N. R., "Self-Selection Models in Corporate Finance," Handbook of Empirical Corporate Finance SET 1 (2008), 37.

Rosen, H., "Housing Decisions and the US Income Tax: An Econometric Analysis," Journal of Public Economics 11 (1979), 1-24.

Shilling, J. D., C. Sirmans, ANd J. F. Dombrow, "Measuring Depreciation in Single-Family Rental and Owner-Occupied Housing," Journal of Housing Economics 1 (1991), 368-83.

Sweeney, J. L., "Housing Unit Maintenance and the Mode of Tenure," Journal of Economic Theory 8 (1974), 111-38.

Verbrugge, R., "The Puzzling Divergence of Rents and User Costs, 1980-2004," Review of Income and Wealth 54 (December 2008), 671-99.

— nomics 38 (Winter 2010), 633-57.

WiLlis, R. J., AND S. Rosen, "Education and Self-Selection," Journal of Political Economy 87 (1979), S7S36. 